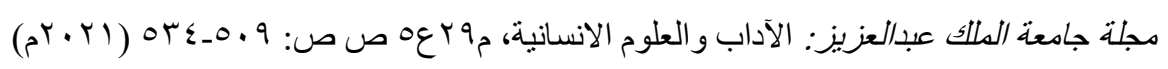

DOI:10.4197/Art.29-5.17

\title{
ظاهرة زواج القاصرات وتأثرها بالطبقة الاقتصادية: \\ دراسة وصفية نوعية
}

\author{
الباحث الاول \\ د. عبله عبد الرحيم محاسنه \\ الدرجة العلمية: دكتوراه تخصص علم الاجتماع \\ محاضر غير متفرغ - جامعة اربا الاهلية \\ الباحث الثاني \\ د. فواز حمدان رويشد العازمي \\ الألرجة العلمية: دكتوراه تخصص علم الاجتماع \\ وزارة الشؤون الاجتماعيتة والعدل - دولتة لكوبت
}

مستخلص هدف هذه الدراسة إلى تسليط الضوء على مدى تأثر زواج القاصرات بالطبقة الاقتصادية من الناحية

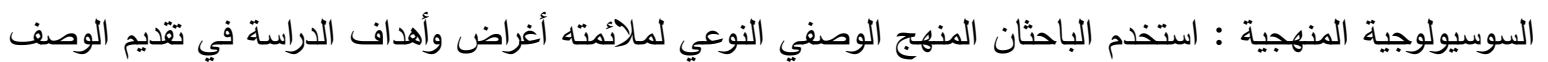
والتحليل على عينة من القاصرات في محافظة جرش وتكونت العينة من بس قاصراً تم اختيارهن بطريقة كرة الثلج من خلال أداة المقابلة المقننة والتي احتوت على محورين المحور الأول هو المعلومات الديمغرافية والمحور الثاني مجموعة أسئلة مفتوحه، تمت مقابلتهن وتم تحليل الاستجابات ومناقشتها وخلصت الدراسة إلى مجموعه من النتائج : كان أهمها

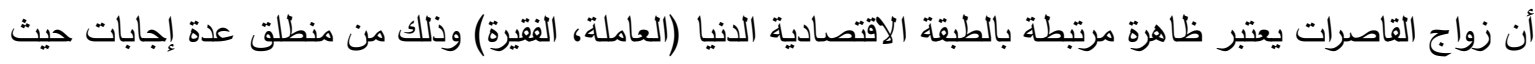

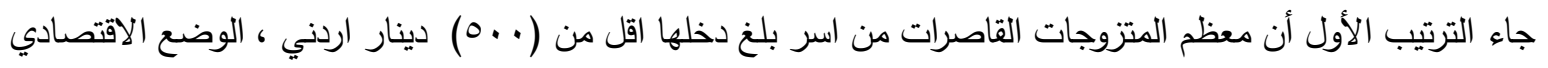
السيء للأسرة جاء كثاني اهم دافع لزواج القاصرات، ولتحسين الوضع المعيشي ، وفي المرتبة الثالثة جاء من اجبرن على زواج بسن مبكره من قبل الأسرة ـ الخلاصة : تتأثر ظاهرة زواج القاصرات بالطبقة الاقتصادية في المجتمع وقد يكون احد اهم أسباب ظاهرة زواج القاصرات هو الوضع الاقتصادية لأسرة الفتاة القاصر . الكلمات المفتاحية: الطبقة الاقتصادية، زواج القاصرات، دراسة وصفية نوعية، ظاهرة.

المجتمعات ذات التعليم المتدني وتدني مستويات

المقدمها

زواج القاصرات او الزواج المبكر هو ظاهرة الدخل بالنسبة للفرد، وكثير من بلدان العالم توجد فيه المجتمعات بمختلف أشكالها، وقد تشترك فيه جميع ظاهرة زواج القاصرات ضمن العن العادات والتقاليد دول العالم، ويكثر في المجتمعات الريفية او والأعراف المتوارثة والبيئة الاجتماعية، وفي الوطن 
بناتهن، ومن الأسباب الأخرى تناقل العادات والتقاليد والتي يصعب التخلي عنها أو معارضتها. ومن بين أبرز الأسباب الأخرى الأوضاع الاقتصادية الأوضية في الأردن والتي تشهد تراجع بدرجات كبيرة في الانباب الاتري الاوضاع التصاديه السنوات الأخيرة بسبب ارتفاع الأسعار وغلاء المعيشة لأني والتي قد تكون سببا مساعدا لتزويج القاصرات فالعائلة ذات مستوى الدخل المتندي والتي تتكون من أفراد

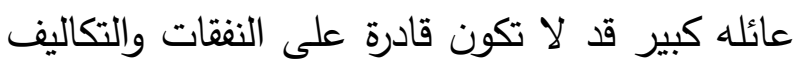
المعيشية التي تلزم العائلة من الأبناء والبنات سواء

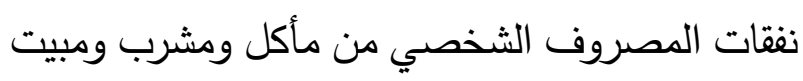
إلى نفقات الدراسة وهذا يعد عامل دفع ويدفع بالكثير من الآباء إلى تزويج بناتهن بسن مبكره في اعتقاد منهم أن هذه الخطوة قد تخفف من أعباء رب الأسرة وتساعد ابنتهم على إيجاد حياة جديدة قد تكون افضل من الحياة الحالية. مشكلة الدراسة : من الحياة تكمن مشكلة الدراسة في اعتبار ظاهرة زواج القاصرات من الظواهر التي لم تثبع بالدراسات بالمجتمعات

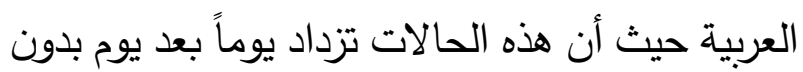

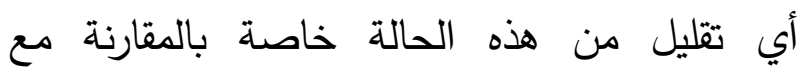
المجتمعات الأخرى حيث أن هذه الدراسة تهتم بدراسة ظاهرة زواج القاصرات وعلاقتها بالطبقة الاقتصادية والتي قد تكون سببا هاما ورئيسيا في ظاهرة بالرغم من وندات تعدد أسباب وجود وتزايد هذه الظاهر إلا أن سبب هاب الأوضاع الاقتصادية له دور بارز مما يعتقد الكثير أن هذه الظاهرة هي مرتبطة بالطبقة الدنيا.
العربي توجد هذه الظاهرة ضمن نطاق العادات والتقاليد والأعراف الموروثة، وقد تزداد نسب زواج القاصرات بالرغم من تقدم المجتمعات وتطورها وارتفاع نسب التعليم فيها فمثل ذلك في المجتمع الأردني تمثل

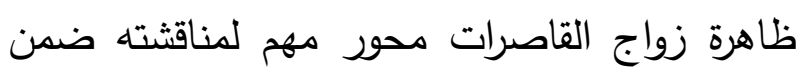

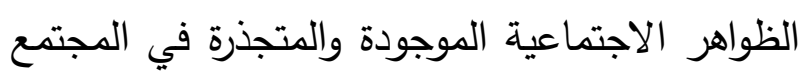
والتي حاولت القوانين والنظم والتشريعات الحد منها لكنها ما تزال حاضره وتحصد المراتب الأولى في الظواهر الاجتماعية، فبين عادات وتقاليد وأعراف لهاف وظروف اجتماعيه واقتصادية وبين قوانين وتشريعات نرى وجود ظاهرة زواج القاصرات متواجد بعدة

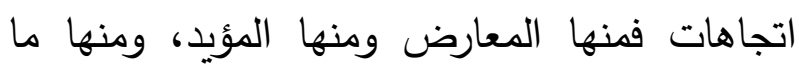
يبحث عن مبررات واستثناءات لتزويج القاصرات،

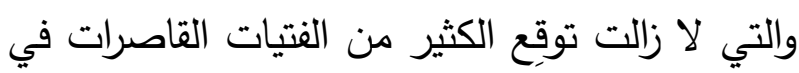
علاقة زواجية وارتباطهن باسَر ومسؤوليات لا تتتاسب

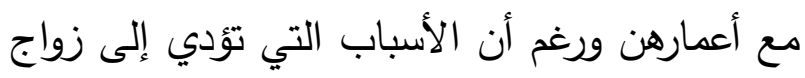

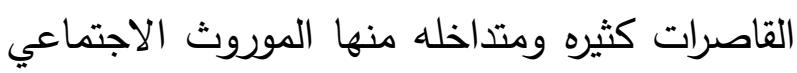
المتمثل بالعادات والتقاليد والأعراف التي تثكل أهمية كبيره داخل المجتمعات الشرقية، ومنها ما يتمثل بظروف اجتماعيه ثقافية ترتبط بتدني مستويات التعليم في المجتمعات ومنها ما يأخذ شكل ظروف اقتصادية قهرية تجبر أهالي الفتيات على تزويجهن بسن مبكره. وكلها عوامل تدفع الأهل إلى تزويج بناتهن القاصرات للحد من النفقات، الحاجة إلى الاستقرار الأمني وأيضاً

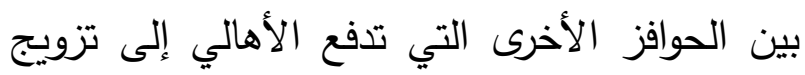


وتأثيرها في زواج القاصرات، بالرغم من وجد عدد كبير

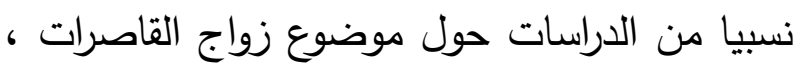
وتعتبر هذه الدراسة متميزة عن غيرها من الدراسات من خلال البحث في الظاهرة من خلال استخدام نظرية التبادل ووصف تجربة القاصرات وقيامها بتوظيف المنهج النوعي لتحقيق أهدافها. - الأهمية العملية / التطبيقية: أن تناول موضوع الدراسة ( اثر الطبقة الاقتصادية في

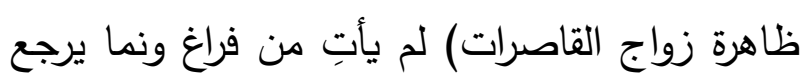

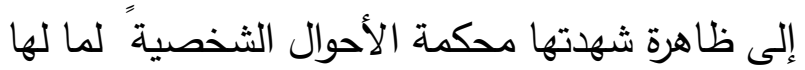
من تأثيرات سلبية على المجتمع وتكمن الأهمية في معرفة وتسليط الضوء على دور الطبقة الاقتصادية في

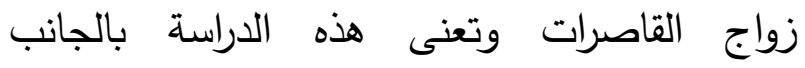
الاقتصادي المادي والذي لم يدرس على حده بشكل

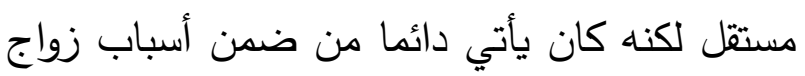
القاصرات وفي هذا البحث عملنا جاهدين على توضيح اثر الطبقة الاقتصادية في زواج القاصرات في محافظة جرش • وتكمن أهمية البحث في تزايد أعداد زواج القاصرات رغم تشديد القوانين والتشريعات الهادفة للتخفيف من هذه الظاهرة وأيضا لما لزواج القاصرات

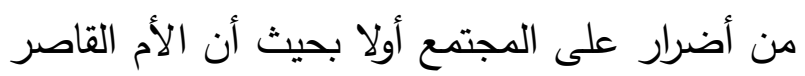

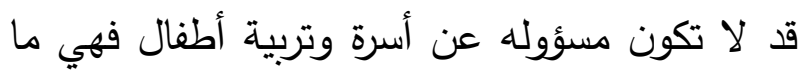

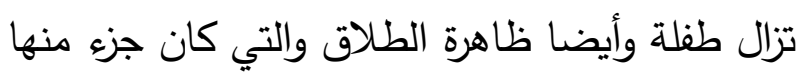
هو بسبب الزواج المبكر وأيضا هناك أضرار تقع على القى

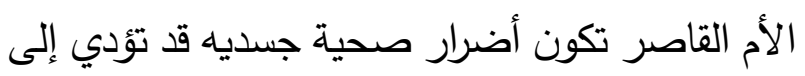
الوفاة بأعمار صغيره بسبب الولادة والإجهاض.

\section{اهداف الدراسة : المات}

1- التعرف الى الخصائص الاجتماعية والديمغرافية

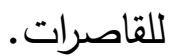

ץ- التعرف الى دوافع الزواج في سن مبكرة.

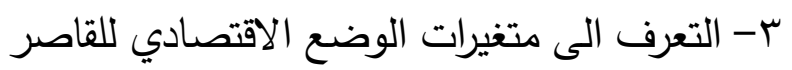
قبل وبعد الزواج.

وفي ضوء الأهداف المنشود للدراسة تم صياغة بعض ترو التساؤلات الرئيسية للتحقق منها من خلال أدوات البحث العلمي التي استخدمت ضمن منهجية البحث. ومن هذا المنطلق فان هذه الدراسة سعت للإجابة

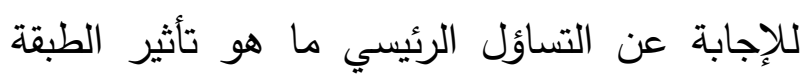
الاقتصادية في زواج القاصرات؟ وذلك من خلا هل الأسئلة الفرعية الآتية:

ا - ما هي الخصائص الاجتماعية الديمغرافية للقاصرات؟ r - ما هي دوافع الزواج بسن مبكرة؟

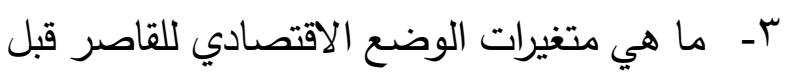
وبعد الزواج؟ أهمية الدراسة: الزواج" برزت أهمية هذه الدراسة في ناحيتين هما: - الأهمية العلمية: بعد الاطلاع على العديد من الأبحاث والدراسات السابقة في مجال ظاهرة زواج القاصرات نبعت الإن الأهمية العلمية للدراسة من ندرة الدراسات في هذا

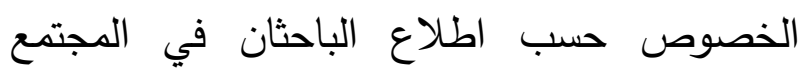
الأردني وخصوا فيما يتعلق بجانب الطبقة الاقتصادية 
يميز بين الطبقة المالكة التي تحدد مكانة الأعضاء على أساس التمايز في توزيع الملكية، وبين الطبقة

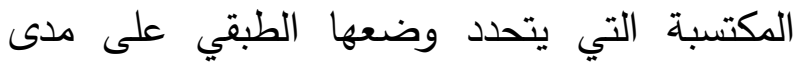
الاستغلال لفرص الحياة، وعلى أساس مجموعة

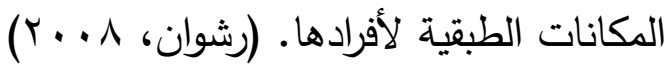
حدود الدراسة: اقتصرت الدراسة على المتزوجات في سن اقل من م| سنة في محافظة جرش.

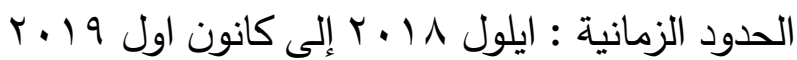
الحدود المكانية: محافظة جرش. زواج القاصرات المفهوم والتطور في أشكال ودواعي

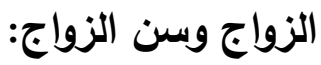
يعد الزواج احد اهم مظاهر الحياة الاجتماعية حيث

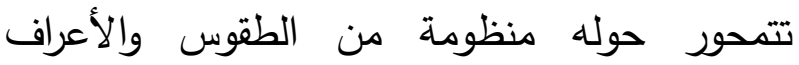
والعادات والتقاليد التي تسعى إلى تتظيمه وتحديد أشكاله واتجاهاته في اطار منظومة من العقائد والتيم السائدة في المجتمع . ( زحلوق ووطفة، ب99 (1)). وقد تطور شكل ومفهوم الزواج بتطور المجتمعات حيث يرى وستر مارك أن منشاء الزواج كأن في لئون

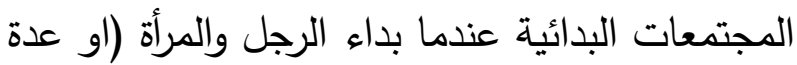

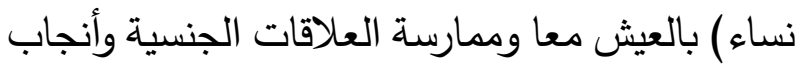
الأبناء وقيام النساء بتربية الأبناء وتدبير شؤون الأسرة

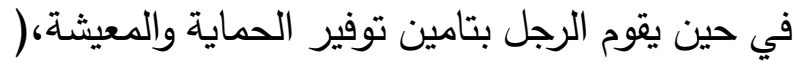

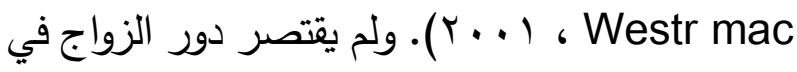
المجتمع على تلبية الغريزة الجنسية لدى الأنسان فمعظم المجتمعات القديمة احتاجت إلى نظام يكفل
وتعتبر الدراسة مهمة لكل من: دائرة الإحصاءات العامة، وزارة التتمية الاجتماعية، مراكز التتمية المحلي، الجمعيات التي تعنى بحقوق الطفل والأسرة، وكليات الدراسات الاجتماعية، وكل من يعنى بموضوع بلهي الطفل والمرأة والأسرة والتتمية. مصطلحات الاراسة : زواج القاصرات : هو ما يطلق على الزواج الذي يكون أحد طرفيه ما دون سن الثامنة عشر حيث يعتبر من هم دون سن الثامنة عشر أطفالا ولا يصح عقد زواجهم بحسب اتفاقيه حقوق الطفل لعام 919 ــ (شبكة الانترنت) الطبقة الاقتصادية : يعد كارل ماركس من أهم المساهمين في نشوء هذا المفهوم وتطوره ولقد كأن جل اهتمامه في الجانب الاقتصادي للطبقة، حيث عرف الطبقة بأنها (تجمع من الأشخاص ممن يقومون بنفس الوظيفة في نظام الإنتاج). ومن أهم ما يميز التعريف الماركسي ما يلي: وجود جماعة من الناس تتشابه من حيث الموقع الذي تشغله في النسق الاقتصادي والاجتماعي،

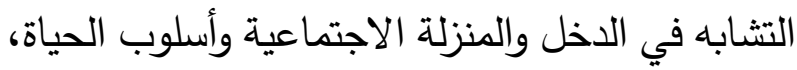
دورها في التنظيم الاجتماعي للعمل وحصولها على

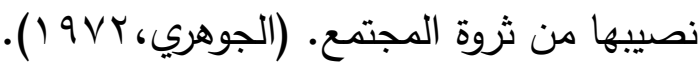
وذهب ماكس فيير إلى تعريف للطبقة من خلال أبعاد أخرى حيث أضاف بعدين آخرين وهما المكانة والقوة في تحديد الطبقة وهو يرى أنهما بعدان يتداخلان في

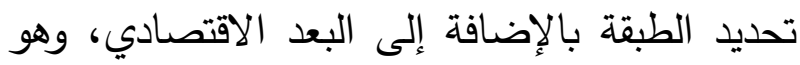


لحقوق الأنسان والحريات التي ضمنتها العديد من

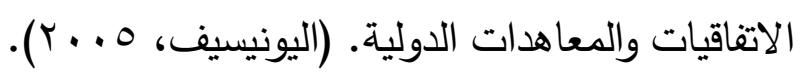
الزواج المبكر في قانون الأحوال الثخصية الأردني

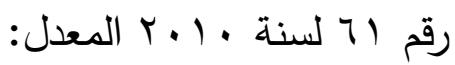
تتص المادة الخامسة من هذا القانون على أنه " يشترط في أهلية الزواج أن يكون الخاطب والمخطوبة عاقلين

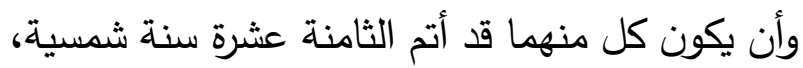
إلا أنه يجوز للقاضي أن يأذن بزواج من لم يتم منهما

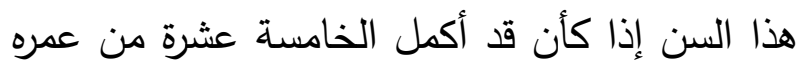
وكأن في مثل هذا الزواج مصلحة تحدد أسسها بمقتضى تعليمات يصدرها قاضي القضاة لهذه الغاية. الهم أسباب ظهور زواج القاصرات: يعتبر الزواج أساسا يقوم عليه المجتمع تنظيما للعلاقات الإنسانية فهو نظام اجتماعي يتصف بدرجة لئرة من الاستمرارية والامتثال للمعايير الاجتماعية القائمة وهو الوسيلة التي يعتمد عليها المجتمع لتنظيم الناحية الجنسية ولتحديد مسؤولية التزاوج الجنسي بين البالغين لونيان

فيه (قطان ، 9 ( )

وتتص المادة (1 أ) من الإعلان العالمي لحقوق

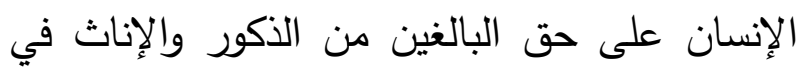
الزواج وتكوين أسره كما تمنع اتفاقية حقوق الطفل لعام(919 (1) زواج الأطفال دون سن الثامنة عشرة. (منظمة الأمم المتحدة). وبالرغم من ذلك فأن الزواج المبكر ما زال شائعا في

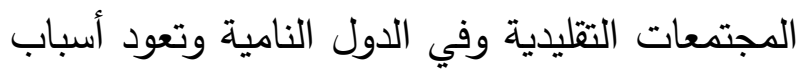
انتشاره إلى مجموعة من العادات والتقاليد او إلى جملة
لها بقاء اسم العائلة وترتيب العلاقات الاجتماعية الناتجة عن العلاقة الجنسية بين الرجل والمرأة وحقوق منح الملكية فكأنت مؤسسة الزواج استجابة لهذه لهاه لهاه الحاجات وليس الزواج حاجات اقتصادية فمثلا أصبحت الحاجة إلى أيدي عاملة في المجتمعات الزراعية من دواعي الزواج كما اصبح اللجوء للزواج وسيلة تحقيق لمصالح الأسر المتصاهرة اقتصاديا

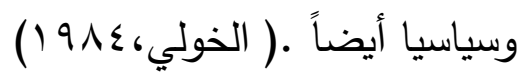
وبتطور مفهوم الزواج ارتفع الزواج في الكثير من المجتمعات، فالمجتمعات كانت تلجأ لتزويج أبنائها وبناتها في سن مبكرة لعدم وجود فرص تلاقي بين الجنسين او للحصول على أيدي عاملة ومع انتفاء هذه ونه الغايات وبتطور المجتمع ودخول التكنولوجيا والانفتاح في العلاقات أصبح بإمكان الرجل والمرأة في اغلب المجتمعات التلاقي في أماكن التعليم والعمل وإقامة علاقات عاطفية بهدف الزواج. ( الخولي، ـ191 (1)

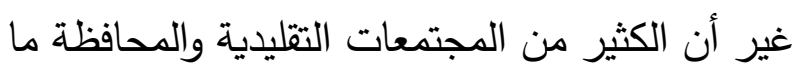
زالت تقوم بتزويج بناتها في سن مبكرة لعدة اعتبارات

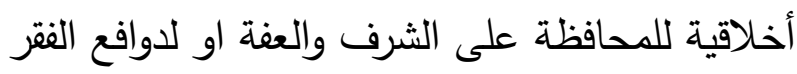
والحاجة. وينتشر الزواج المبكر في الدول النامية التي ما زالت الأعراف والعادات والتقاليد والموروثات الثقافية هي السائدة فيها، والتي تعتبر من اهم الأسباب الزواج المبكر • وتعرف المنظمة اليونيسيف الزواج المبكر

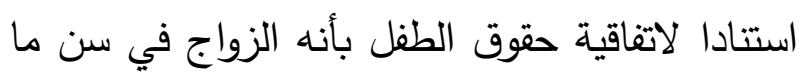

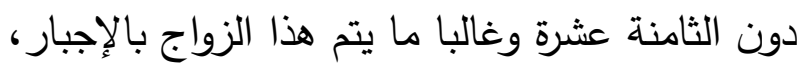
كما تعتبر المنظمات الدولية الزواج المبكر انتهاكا 
اليونيسيف أن حوالي نصف عدد الفتيات في بعض الدول يتم تزويجهن دون سن الثامنة عشرة نتيجة

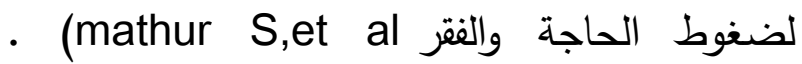
,2003)

في المجتمعات المحافظة تلجأ الأسر إلى تزويج بناتها

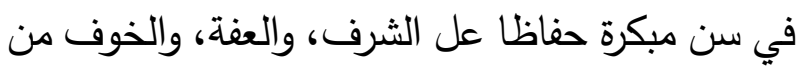
الانحرافات الجنسية. حيث غالبا ما ترى هذه الأسر ولعر أن شرف العائلة هو في الحفاظ على عذرية الفتاة،

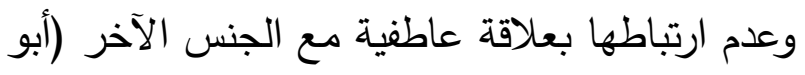

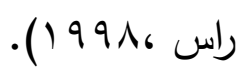
يسود الزواج المبكر في المجتمعات الريفية والقروية حيث ما زالت العادات والتقاليد قوية جدا والمتعلقة لهن بزواج الصغار والأقارب كالمجتمع الصعيدي في مصر ومثيله في الدول العربية وغيرها. بالإضافة إلى والى لي

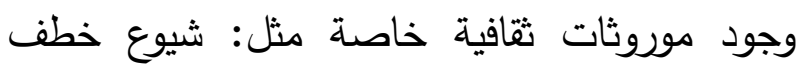
الفتيات وإجبارهن على الزواج من مختطفيهن في أثيوبيا، كما يسود في بعض دول أفريقيا الاعتقاد بأن

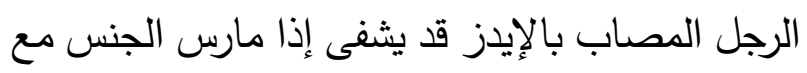
فتاة عذراء (Y. . . Y. Yath Vander). في ظروف فقدان الأهل او انعدام الأمن في فترات

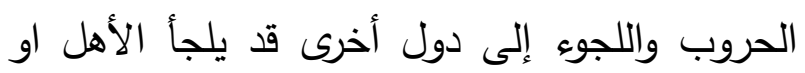

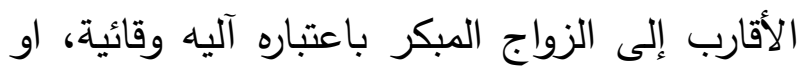
استراتيجية للبقاء وهو ما يطلق علية (زواج السترة) كما وضع اللاجئين السوريين في مخيم الزعتري

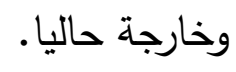

من المتغيرات التي تشجع علية باعتباره وسيلة لحماية

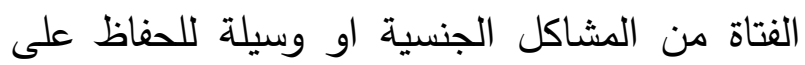
الشرف كتزويج الفتاة من مغتصبها او تزويج اللاجئات

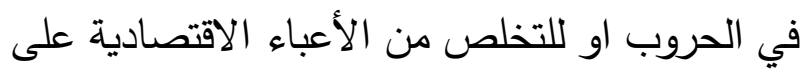

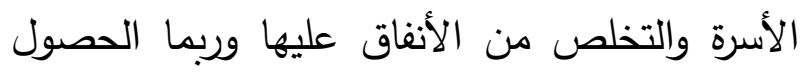

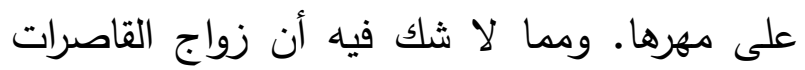

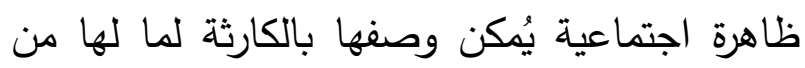

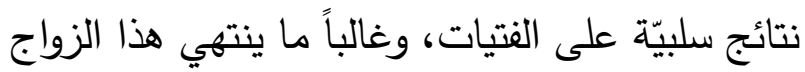
بالفشل مع وجود طفل أو أكثر مع فتاة لا تعرف كيفيّة تربيتهم، وينتشر هذا الزواج في المناطق الريفيّة بشكل

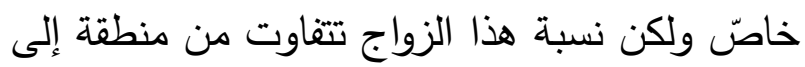

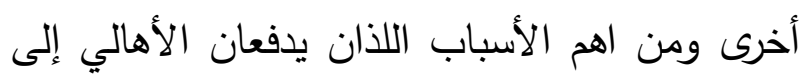

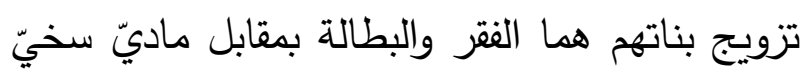
وقد يكون تفشّي الجهل من أهمّ أسباب موافقة الأهل

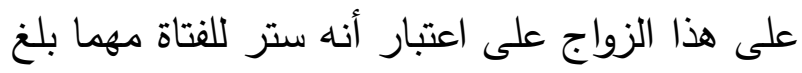

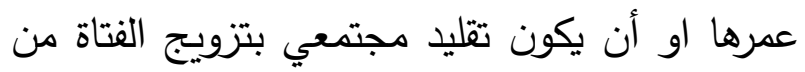

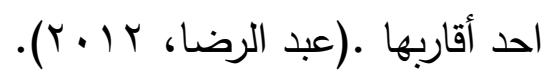
تتعدد أسباب زواج القاصرات فمنها ما هو متعلق بالعادات والتقاليد بالإضافة إلى الممارسات الثقافية ومنها ما لله دواعي اقتصادية وظروف خاصة: يعتبر فقر الأسر من العوامل الاقتصادية التي تجبر

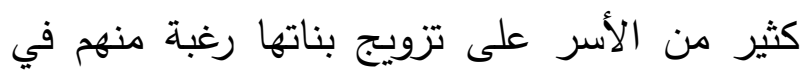

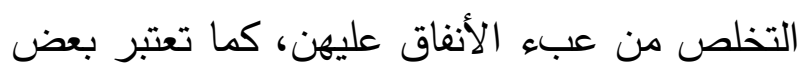

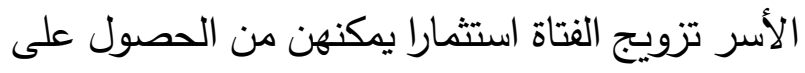
المال كما في الثقافات التي يعطي فيها الرجل مهرا للمرأة مقابل الزواج منها، كما يسير تقرير لمنظمة 
1- أن يكون الخاطب كفوا للمخطوبة وفق عناصر الكفاءة المنصوص عليها الفقرة (أ) من المادة الهاد ( Y (Y) من قانون الأحوال الشخصية. r- أن يتحقق القاضي من الرضا والاختيار التامين،

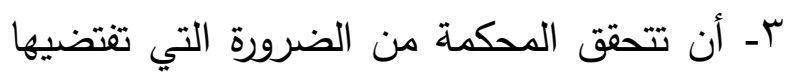

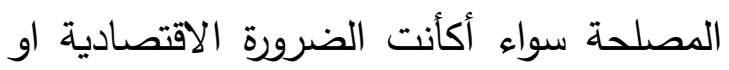

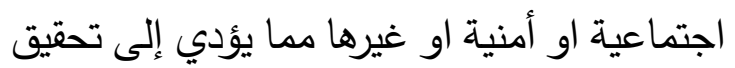
منفعة او درو مفسدة وبما تراه مناسبا من وسائل

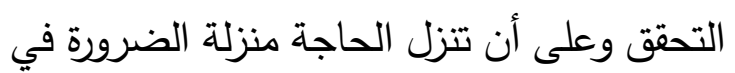
ذلك.

ـ- أن تراعي المحكمة ما أمكن وحسب مقتضى الحال وجود مصلحة ظاهرة في الإذن بالزواج

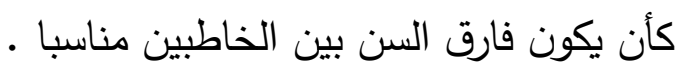
๑ـ أن لا يكون الزواج مكررا وأن لا يكون الزواج

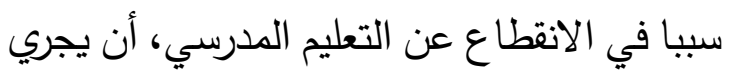
العقد بموافقة الولي وذلك مع مراعاة أحكام المواد

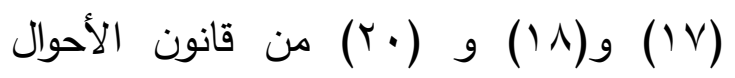

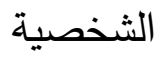
7- أن تنظم المحكمة ضبطا رسميا يتضمن تحقق

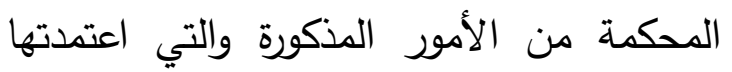
لأجل الأذن بالزواج وتتسيبها بخصوصها ثم ترفع

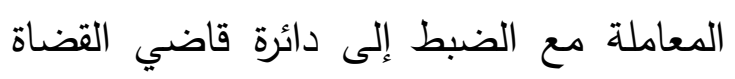
لتدقيقها واتخاذ القرار المناسب بشأنها. بعد صدور موافقة قاضي القضاة تسجل حجة أذن بالزواج حسب الأصول يتم إجراء عقد الزواج بعد
يشير تقرير نشرته هيئة الأمم المتحدة لتمكين المرأة

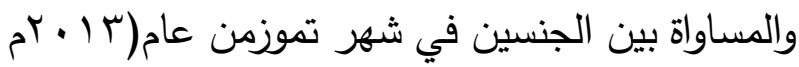
)بعنوان (العنف المبني على النوع الاجتماعي وحماية الطفل في مجتمع اللاجئين السوريين في الأردن)

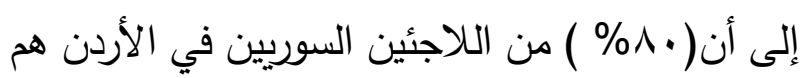
من النساء والأطفال. وقد صنف التقرير الزواج المبكر

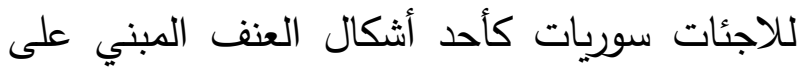
النوع الاجتماعي وأشار التقرير أيضاً إلى رواج الزواج

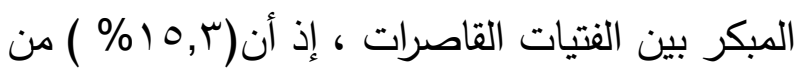

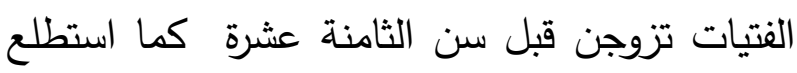
التقرير آراء عينة الدراسة بخصوص السن الملائمة

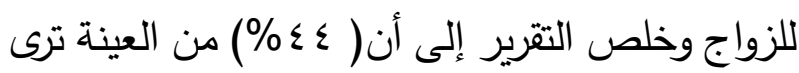

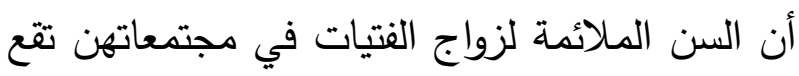

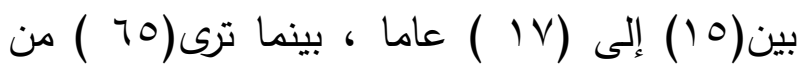

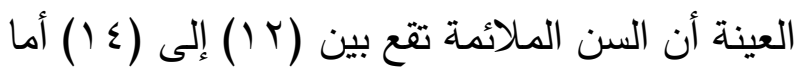
واكد التقرير على أنه من ابرز التحديات التي تواجه النساء والأطفال في مخيم الزعتري هي العنف الجسدي الني

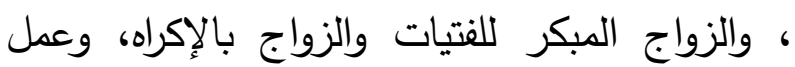

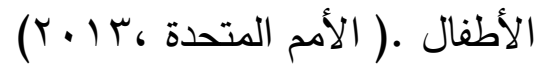
وفي الأردن فأن السن القانونية للزواج بحسب قانون

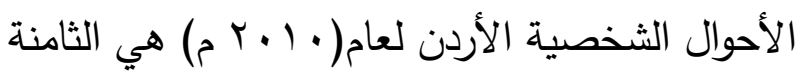
عشر غير أنه يسمح للقاضي بتزويج من هم في سن الخامسة عشر في حالات استثنائية حددها قاضي هني

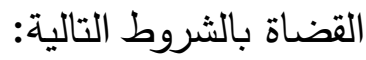


1 1 ) عاما، إلى (TYT ) ) عقدا لفتيات قاصرات، وسجل \& ع عقدا لفتيان قاصرين من مجمل عقود الزواج العادي المكرر بنسبة(7, 1 ( \%)وذلك بانخفاض

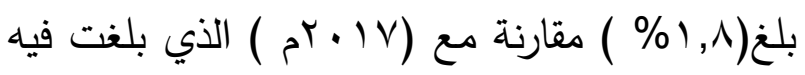
نسبة تزويج القاصرات ـ ع, ب ا \% حيث أن "التعليمات الجديدة والمحدثة لزواج القاصرين والقاصرات صدرت

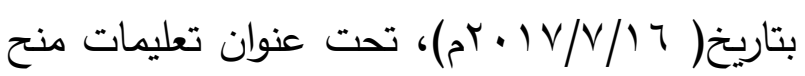
الإذن بالزواج لمن أكمل خمس عشرة سنة شمسية من عمره ولم يكمل الثامنة عشرة رقم ( () لعام (V l • r م) صادرة بموجب الفقرة (ب) من المادة ( • () من قانون

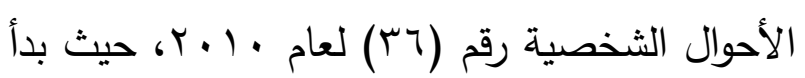

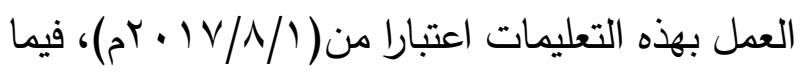
ألغيت تعليمات منح الإذن بالزواج لمن هم دون سن

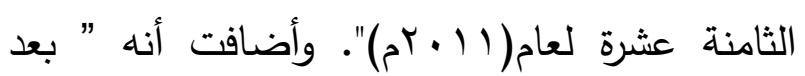
صدور التعليمات الجديدة لمنح الإذن بالزواج للفئة العمرية( 10 (1) 1 عاما، بدأت مكاتب الإصلاح والتوفيق الأسري النظر في طلبات منح الإذن بالزواج، حيث استقبلت في الربع الأخير من عام(VI + r م) بحدود (9 • ( ) طلبا لزواج القاصرين، ومنحت الإذن

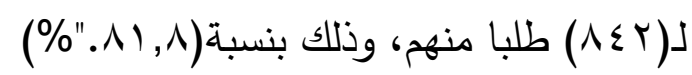

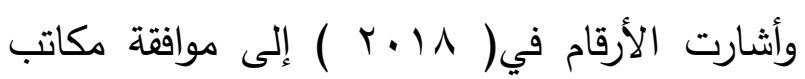
الإصلاح والتوفيق الأسري في مختلف محافظات

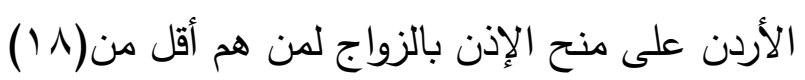
عاما بنسبة بلغت(س, \%97\% ) من الطلبات، بينما رفضت (\%r,v) فتط من الطلبات، حيث تقدم لهذه المكاتب(TVRO) طلبا لزواج القاصرين، وتم
التحقق من انتقاء الموانع الشرعية والقانونية. (موقع القسطاس الإلكتروني، • r • ( ). وفي توضيح لنسب ظاهرة زواج القاصرات في الأردن لآخر (0) سنوات: فحسب التقارير، فقد بلغ عدد عقود الزواج التي كانت فيها الفتيات القاصرات طرفا، (YTV I I ) عقدا، في حين عرض التقرير تزويج(ع میر · ) فتاة قاصرا

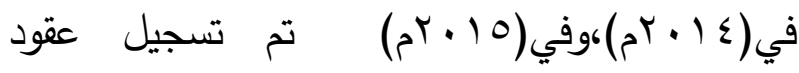

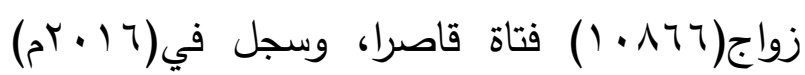

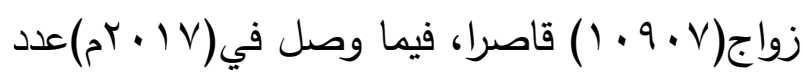
زواج الفتيات القاصرات إلى( عاء • ()، أما

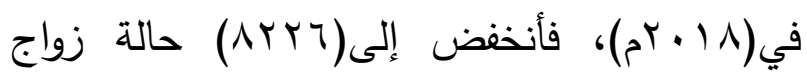

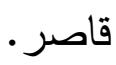
أن "زواج الفتيات دون سن الثامنة عشر يُعد شائعا في الأردن، لكن ما أثار معارضتهم هو ارتفاعه خلال

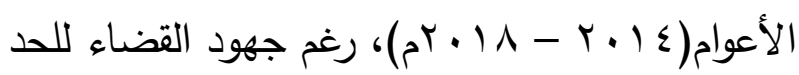
من تزويج القاصرات." وفي تقرير دائرة قاضي القضاة، تسجيل(7 9 ( )عقد زواج خلال(1/ • rrم) وكان فيها كل من الزوج والزوجة أقل من(1 ( )عاما "أسر قاصرة“، حيث

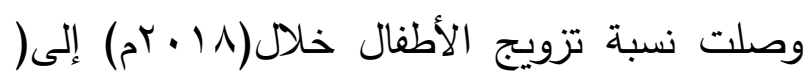

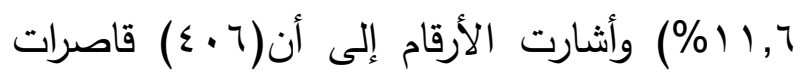
مطلقات تم تزويجهن للمرة الثانية في عام(^ ا • r م) قبل بلوغهن (1 ا ) ماما. ووصل عدد عقود الزواج خلال(^ ا •r م)التي كأن فيها أحد الزوجين أو كلاهما ضمن الفئة العمريـة(0 10 
التي يحققها الأفراد في سلوكهم المتبادل حجر الزاوي لهذه النظرية (السيد، م . . ب).

وتشير النظرية إلى أن التبادل لا يقتصر على التعامل المادي والاقتصادي في السوق بل أن أفراد المجتمع قد يتبادلون مع بعضهم أشياء غير مادية مثل: الخدمات او المشاعر وهذا فان الأفراد يسعون للزواج بوصفه عملية تفاعلية داخل المجتمع رغب في تحقيق أهداف وغايات اجتماعية تستهدف القبول الاجتماعي من قبل أعضاء جماعتهم والحصول على احترامهم؛ مما يزيد من اعتباره الاجتماعي، ومكانته الاجتماعية، ولا سيما أن المجتمع يعد الزواج من القيم الأساسية التي يجب على الأفراد الالتزام بها. (خليل، 99 ( )). إن الزواج مهم، ويسعى إليه الأفراد لأنه يلبي حاجة اجتماعية، وذلك من اجل تحقيق ستة عوامل رئيسية لهم وهي: تحقيق السعادة الزوجية، والعشرة الحسنة، والإحساس بالأمن، تربية الأبناء، وتحقيق الذات والاستقرار العاطفي، وتطبيق ثقافة المجتمع، لذا فان رغبة الفرد في الحصول على الزواج قد تكون قائمة على الرغبة في تبادل المصالح للطرفين حسب نظرية التبادل الاجتماعي. ( نادلسون (919)). نظرية الدور :

تعتبر هذه النظرية أن عملية التشئة الاجتماعية هي عملية تعلم اجتماعي فالطفل يكتسب الصفات والمعايير والسلوكيات المقبولة عن طريق الملاحظة والمحاكاة والتقليد لوالدية. كما أن التشئة: وهي عملية تربوية مستمرة تسهم في ترسيخ المكتسبات من قبول(r فقط. في حين انخفضت نسبة زواج القاصرات في الأردن

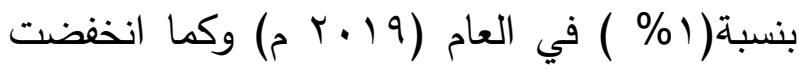
عقود تزويج القاصرات (أقل هن 1 / إماً)

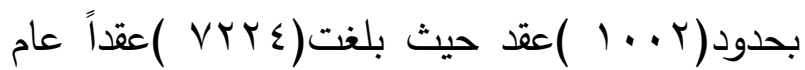

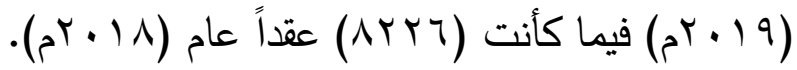
وذلك وفق ما جاء في التقرير الإحصائي السنوي لعام(9 1 •rr) والصادر عن دائرة قاضي القضاة الأردنية. (دائر قاضي القضاة، • ب • بم). وفي محافظة جرش يحدث متوسط( • ع ) حالة زواج قاصر شهريا اغلبهم من الجنسية السورية والجنسية الفلسطينية وبلغت نسبة زواج القاصرات في محافظة جرش في عام(1 1 • r م)، (19 1 عقد لقاصرات من

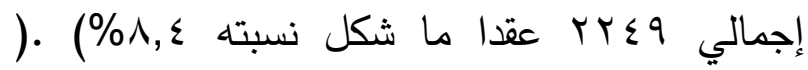
المحكمة الشرعية / محافظة جرش). من اهم النظريات المتعلقة بالطبقة الاقتصادية وزواج

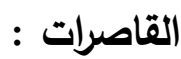
نظريسة التبادل: - ن تعتبر نظرية التبادل أن الناس في عملية تفاعل اجتماعي وهم يتبادلون أنماط السلوك وهي تنظر للمجتمع بوصفه شبكة من التفاعلات والتبادلات المنظمة عن طريق معيار تبادلي (عثمان ، ، . . ب) وتعتبر هذه النظريـة الفرد وحدة التحليل فيها واهم ما فيها هو أن الحاجات والأهداف الخاصة هي المحرك الأساسي، او الدافع الرئيسي للأفراد، وان المكافآت 
ومن هذا المنطلق فأن هذه الأدوار والمكانات غير

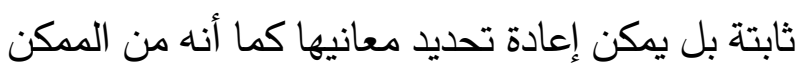
إعادة تفسير الرموز والاتجاهات لدى الفرد والتي اكتسبها من خلال عملية التفاعل مع كافة مؤسسات

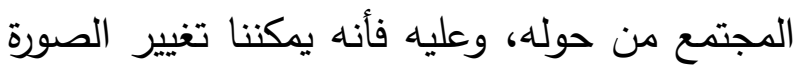
الإيجابية للزواج المبكر عند المجتمع والمساهمة في تغيير نظرة الأفراد له كوسيلة للتخلص من آثاره السلبية على الفرد والمجتمع. الادراسات السابقة :

تشير معظم الأدبيات التي تتاولت موضوع زواج القاصرات من دراسات سابقة وتقارير وأبحاث دولية إلى وجود دوافع اجتماعية وعادات وتقاليد تثجع الزواج المبكر من باب الحفاظ على العفة والثرف وكثرة النسل بالإضافة إلى وجود دوافع اقتصادية تتمثل بال في الفقر وكبر حجم العائلة فيشكل الزواج المبكر وسيلة للتقليل من حجم الإعالة في الأسر وكما تبين هذه الدراسات أثار الزواج المبكر من مخاطر صحية الإنه

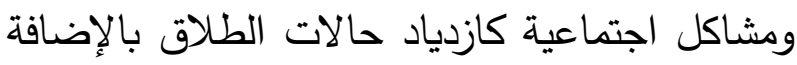

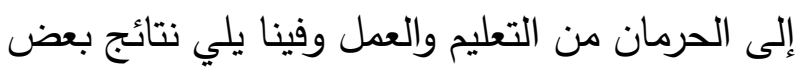

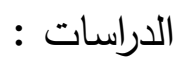

- دراسة (سرور 17 • ب)" زواج القاصرات في الأسرة الريفية المهجرة" هدفت الدراسة لمعرفة الأسباب التي أدت إلى زواج القاصرات وتأثير الظروف الاجتماعية الاستثنائية التي تعرضت لهاج الأسرة خلال فترة (التهجير )، واستخدم المنهج الاثنوغرافي وهو توصيف لهابف

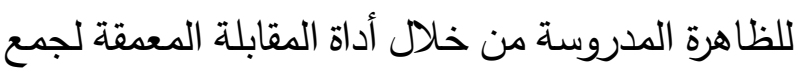

السلوكيات والقيم والعادات عن طريق التعزيز لكل ما هو مقبول كسلوك أنثوي او ذكوري وبالتالي بناء أدوار اجتماعية قائمة على الجنس، تشكل إطار وهوية لكلا

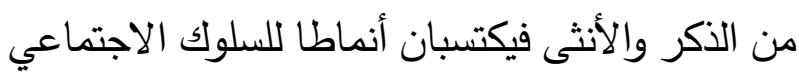

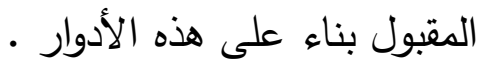
كما أن التتشئة الاجتماعية تشكل تدريبا للأشخاص هله على أدوارهم المتوقعة منهم بناء على المعايير والقيم والمعارف والاتجاهات المكتسبة ، بغرض تسهيل قبولهم واندماجهم في المجتمع في اطر الثقافة السائدة

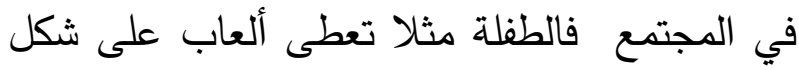

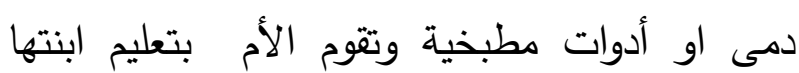
المراهقة الطبخ ومهارات التدبير المنزلي تعزيزا للدور المتوقع منها أن تقوم به في المستقبل ، ويعزز الخجل والحياء عند الفتاة المراهقة كسلوك محمود بينما تواجه أي محاولة للفتاة المراهقة بإبداء الاستقلالية او التغيير

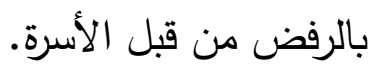
كما تعزز صورة ومكانة المتزوجة في المجتمع حيث هيث تميل المجتمعات المحافظة على تلقين الفتاة الفكرة المتمثلة في كون المرأة المتزوجة افضل من العازبة وفي المقابل فأن الطفل الذكر يعطى ألعاب كالسيارات والمعدات الآلية ولا يطلب من المراهق المساهمة في لهي أعمال المنزل ويشجع سلوك المراهق القوي ويعاب علية الخجل والحياء فيسهل على الفتاة تقبل دورها كزوجة ولو في عمر مبكر بينما يؤخر الرجل زواجه حتى يصبح له مقدرة مالية على تحمل تكاليف الزواج

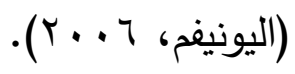




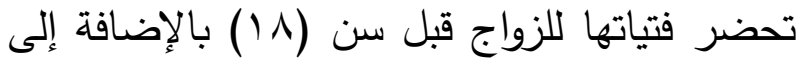
مقابلة عدد من العاملين في تلك العيادات. وأوضحت الدراسة أن الفتيات تعاني من زيادة مخاطر الإصابة بمشكلات صحية مختلفة مثل مخاطر الوفيات أثناء الولادة والأمراض المرتبطة بالولادة، وترى الدراس أن يون هناك تربية جنسية صحية، وإرشادات لمنع الحمل المبكر ، والعنف الأسري. -اجرى (كرادشة r 1 • r) دراسة "زواج الإناث المبكر : محدداته وأثارة الديموغرافية (دراسة تحليلية)" حيث هدفت الدراسة إلى كثف ودراسة وتحليل محددات زواج الإناث المبكر سواء كأنت اجتماعية او اقتصادية وتبيأن اهم أثار هذه الأنماط الزواجية على سلوك المرأة الديموغرافي في الأردن خلال فترة زمنية محددة تمتد

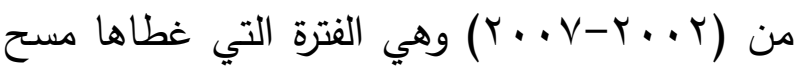
السكان والصحة الأسرية في الأردن لعام V... واشتملت على السيدات اللواتي سبق لهن الزواج وتتراوح أعمارهن ما بين 10- 9؛ وقد تم استخدام عدة طرق إحصائية تراوحت بين البسيطة والثنائية والمتعددة لتحليل بيانات الدراسة وقد خلصت الدراسة إلى عدة نتائج منها: تكمن خطورة الزواج المبكر خاصة زواج الإناث في زيادة الأخطار الصحية سواء على الأمهات الصغار او على مخرجات الحمل لديهن كما ترتبط بالزواج المبكر عدة مشكلات صحية مثل : تسمم الحمل، او الإجهاض كاو اختناق الأجنة وتدخل الأطباء للمحافظة على حياة الأم والولادات المبكرة ، والإجهاض القسري ، وحمى النفاس وزيادة
البيانات وتكونت العينة من (OV)، وتوصلت الدراسة إلى مجموعة من النتائج كأن من ابرزها : التهجير سبب أساسي في زواج القاصرات، زواج القاصرات كأن نتيجة رغبة الفتاة وأسرتها بالحصول على حياة افضل وتامين استقرار مكاني كحد اعلى من طموح الرضا، تدني مستوى التعليم لعينة البحث، تعاني الفتيات القاصرات من أعباء في دورهن الأسري نظرا إلى عدم قدرتهن على القيام بمسؤوليات الزواج. - دراسة (سليم ومحمد 10 • ب) " الزواج المبكر لمن هم دون سن 1/ سنة ظاهرة من ظواهر العنف الأسري ضد الأطفال" هدفت إلى معرفة أهمية الزواج المبكر سلبياته وإيجابياته وقامت الدراسة على المنهج الوصفي بطريقة العينة القصدية من خلال أداة الاستبيان التي وزعت على أفراد العينة المكونة من (1Or) مبحوثة من طالبات كلية التربية قسم رياض الأطفال في جامعة بغداد وتوصلت الدراسة إلى إلى مجموعه من النتائج من ابرزها : أن الزواج المبكر يعتبر عنفاً اسرياً ضد الأبناء، هنالك سلبيات كثيره للزواج المبكر منها حالات تؤدي للطلاق عدم قدرة الزوجين على تحمل المسؤولية.

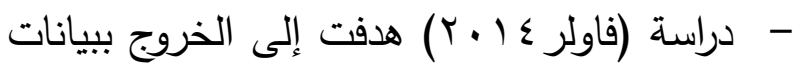
وتوصيات تعزز من رسائل التوعية التي تقوم بها المنظمات الدولية، في حملاتها للحد من زواج القاصرات، واستهدفت الباحثة العيادات الصحية في مدينة اربد، وعقدت مقابلات مع المراجعات السوريات اللواتي هن أصلا متزوجات قاصرات، او الأسر التي 
في المحافظات الأكثر فقراً، والمناطق الجغرافية التي تنتشر بها هذه الممارسات أثتتت أن هذه الظاهرة في

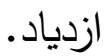

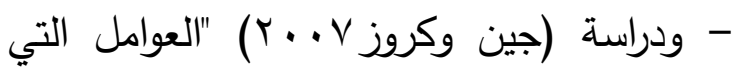

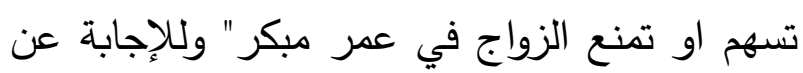
تساؤل الدراسة اعتمدوا على المسوحات الديموغرافية

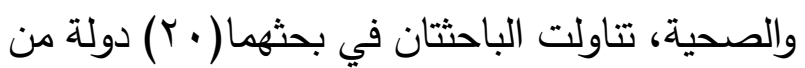
من الدول التي تتنشر فيها ظاهرة زواج الأطفال، بما يسمى (البؤر الساخنة)، وقد تم تحليل (r I) عاملا من العوامل المسببة للخطر والحماية. وقد بين البحث أن أربعة عوامل ذات ارتباط وثيق بزواج الأطفال:

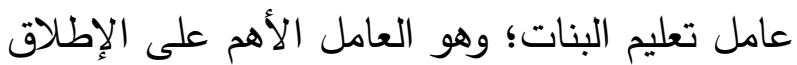

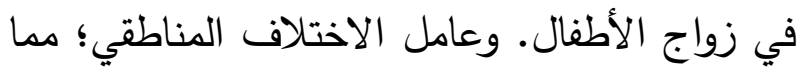
يستدعي التركيز على المناطق الأكثر تعرضا لزواج

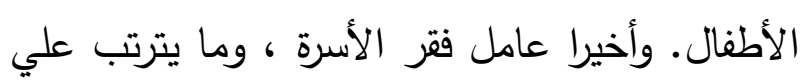

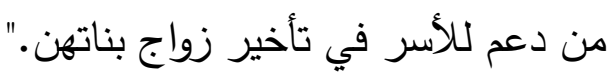

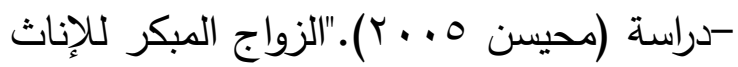
في منطقة القدس أبعاده وآثاره دراسة تحليلية" هدفت لترات الدراسة إلى الوقوف على آثار وأبعاد الزواج المبكر للإناث في منطقة القدس ومعرفة اتجاهات المتزوجات مبكراً ومعرفة علاقة بعض المتغيرات بهذا الزواج واستخدمت الدراسة العينة العشوائية من خلال أداة الإستبيان لجمع البيانات وتكون مجتمع الدراسة من الندان

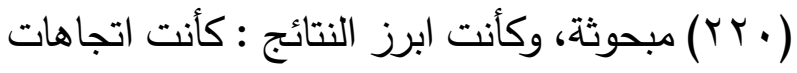

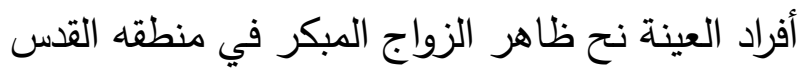

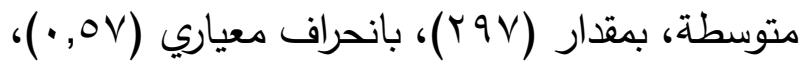

احتمالات حدوث وفيات الأطفال الأجنة لديهن ارتفاع مستوى الخصوبة الفعلية للإناث اللواتي تزوجن مبكرا يزيد فرصة تعرضها لاحتمالات الحمل والأنجاب وبالتالي زيادة حجم العائلة. يترتب على الزواج المبكر

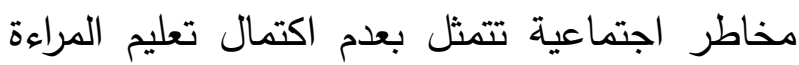
وعدم القدرة على تتظيم النسل وزيادة معدلات الإعالة وعدم القدرة على تلبية حاجاتها النفسية والاجتماعية والمادية وزيادة شعورها بالحرمان وزيادة معاناتها في المجتمع.أن الإناث اللواتي تزوجن بأعمار مبكرة لا لاديان

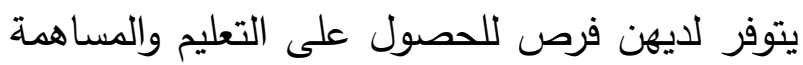
بسوق العمل.زيادة احتمال زواج الإناث بسن مبكرة زاد من احتمال تفكك اتحاداتهن الزواجية كحصول الطلاق

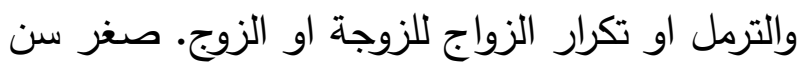

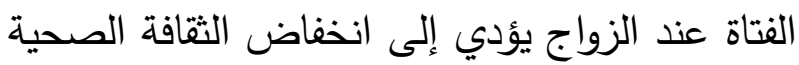
لايها واعتمادها على الممارسات التقليدية الموروثة مما يؤثر سلبا على قدرتها في تنظيم أسرتها والعناية

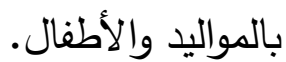
- دراسة ( بابفام، (1) • (Y)، قام بها على المنطقة العربية والتي أوضحت أن اعلى نسب لزواج الأطفال في أفقر البلدان المتمثلة في اليمن والسودان والصومال، أما مصر فهي اكبر بلد عربي من حيث

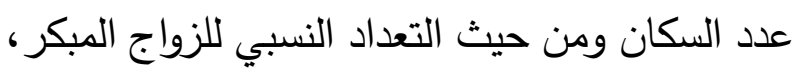
حيث يمثل الزاج المبكر في مصر حوالي ها 1\% من الزيجات، حيث تصل نسبة الفتيات المتزوجات ما بين

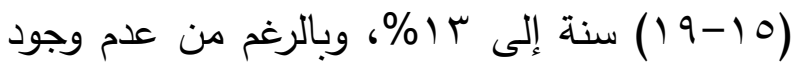
دراسة قومي في هذا المجال، إلا أن البحوث المتناثرة 
التعليم ، والمهارات الوطنية وتنفيذ برامج تعليمية حول

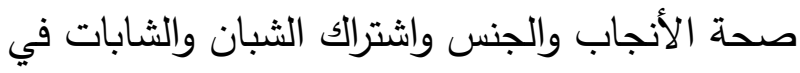
وضع البرامج وتنفيذها.

ما يميز الاراسة الحالية عن الاراسات السابقة : من الملاحظ ان الدراسات اهتمت بظاهرة زواج القاصرات ودرستها من عدة جوانب مختلفة سواء في العالم او في الوطن العربي وجاءت اغلب الدراسات شامله في دراستها للأسباب التي تدفع زواج القاصرات

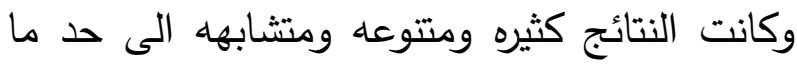
تعددت من أسباب اجتماعيه وثقافية الى أسباب اقتصاديه او حتى أسباب قصريه كسبب الهجرة والحروب وغيرها ومن الملاحظ ان هناك أسباب مشتركه نتجت عن تزويج القاصرات الا ان هذه الدراسات لم تدرس اثر الطبقة الاقتصادية في زواج القاصرات ومدى تاثيرها في هذه الظاهرة على حد سواء والذ ارتأى الباحثان لإدراجهما في هذه الدراسة الحالية.

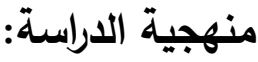

في هذا الفصل نتعرف على الخطوات العملية التي استخدمت في أنجاز الدراسة من خلال تحديد المنهجية الملائمة للإجابة على أسئلة الدراسة، أضافه إلى الى لى وصف مجتمع وعينة الدراسة المستخدمة وجمع البيانات، كما تضمن تحليل المقابلات الذي اتبع وعيك للوصول إلى نتائج الدراسة.تم استخدامالمنهج النوعي الوصفي لملائمته أغراض واهداف الدراسة في تقديم لتاني الوصف لاثر الطبقه الاقتصادية على زواج القاصرات في محافظة جرش والذي سمح للمبحوثات مجالاً
لا توجد فروق ذات دلالة إحصائية بين اتجاهات المتزوجات مبكرا وبين متغيرات الدراسة سوى متغير البنية الجسدية للزوجة قبل الزواج لصالح اللواتي كأنت صحتهن ممتازة ومتغير عدد أفراد الأسرة للزوجة قبل لتراجل الزواج بحيث كلما زاد عدد أفراد الأسرة كأنت الاتجاهات اعلى نحو الزواج المبكر

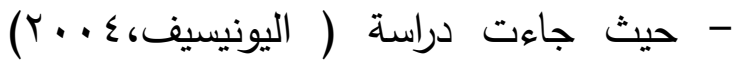
أجرتها منظمة الأمم المتحدة للطفولة إلى أن المكانة الاجتماعية المتدنية للمراءة هي سبب رئيسي لحدوث الزواج المبكر حيث هناك اعتقاد سائد في بعض هضئ

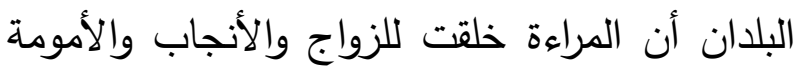
فحسب ، وأن الفتيات تشكل استتزافا لموارد الأسرة لذلك لكراءة تلجأ الكثير من الأسر في الدول النامية إلى تزويج

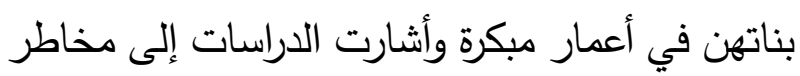
الزواج المبكر الصحية ، وضعف الثقافة والمعرفة الصحية والجنسية التي تحصل عليها الفتاة بسبب تركها للمدرسة وزواجها في سن مبكرة بالإضافة إلى حرمانا من التعليم والعمل ، حيث تشير النتائج إلى أن الفتيات المتعلمات وبخاصة في المرحلة الثانوية تتوافر لديهن فرص عمل اكبر وتزداد قدرتهن على اتخاذ القرار وكذلك يزداد وعيهن حول أنفسهن ومجتمعهن ويرجح أن يكن اكثر قدرة على اتباع وسائل تنظيم

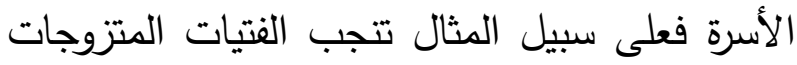
ممن أنهين مرحلة الدراسة الابتدائية نصف عدد

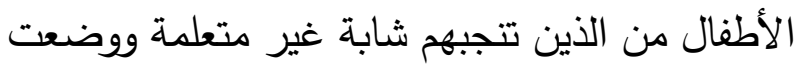
الدراسة عدة استراتيجيات لحل المشكلة منها ترويج 
الفتيات المتزوجات بأعمار اقل من ^1 انسه في محافظة جرش وبلغ حجم العينة بr فتاة .

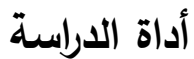

طبقت الدراسة أسلوب المقابلة المعدقة ، في الحصول على البيانات، حيث أجريت مقابلات للقارصرات بشكلٍ مباشر في المكان المناسب لهن وسؤالهن عن اثر الطبق الاقتصادية في زواج القاصرات وابرز الأسباب التي دفعت بهن للزواج بس مبكرة؛ وبالتالي

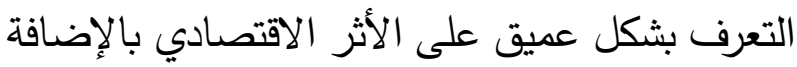

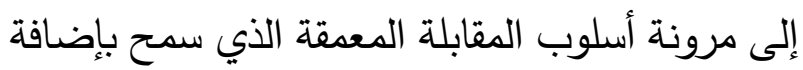
أو حذف أو تبديل الأسئلة للتعرف على المزيد من لئل

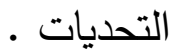

Semi- وتتميز المقابلة العميقة شبه محكمة البناء structured Interview تضمن قائمة بالأسئلة المكتوبة التي لابد من تغطيتها خلال المقابلة، دون الحرص على اتباع ترتيب الأسئلة خلال المقابلة، وبالتالي التمتع بقدرٍ من التحكم في كيفية صياغة بنية المقابلة وكيفية استجابة المستجيبة، مع الاستعداد لامكانية طرح أسئلة جديدة وبالتالي ترك ولئه مساحة للتلقائية من جانب الباحثة والمستجيبة للمقابلة وبالتالي فهم دقيق وواسع حول التجارب المعيشة

$$
\text { للفرد. (بايير وليفي، } 0 \text { 1 • ب). }
$$

وقام فريق العمل البحثي بتجربة دليل المقابلة على ولى (r) من المتزوجات بسن مبكرة ؛ لاختبار دليل المقابلة من حيث اللغة وحساسية الاسئلة ومستوى فهم الأسئلة، وإجراء التغيير المناسب.
للتعبير عن تجاربهن الثخصية ومشاكلهن التي يواجهنها. ويهتم المنهج النوعي بوصف الواقع المُعاش كما هو تماما واستتتاج الدلالات والبراهين من موقع الحدث.

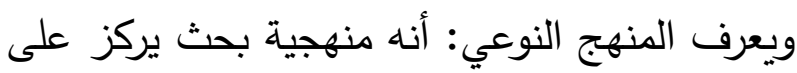
وصف الظواهر والفهم الأعمق لها، وينطلق من فلسفة أن الحقيقة ليست واحدة وأنها متعددة ومتغيرة وتتشكل

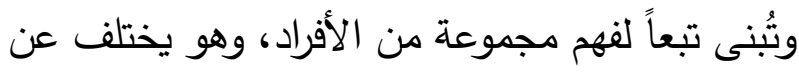

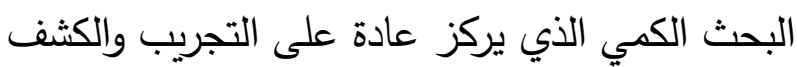
عن السبب أو النتيجة بالإعتماد على معطيات عددية، والسؤال في المنهج النوعي مفتوح حتى النهاية، ويهتم بالعملية والمعنى أكثر من اهتمامه بالسبب والنتيجة

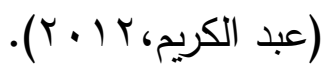

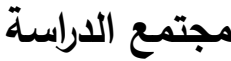

يشتمل مجتمع الدراسة على جميع المتزوجات القاصرات في محافظة جرش حيث قام الباحثان بالحصول على إحصائية اعداد المتزوجات بس مبكره

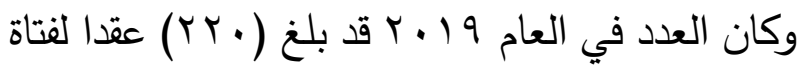
قاصر دون السن 11 وتم اخذ عينة قصدية لما يتناسب مع إمكانية الباحثة في الوصول إلي مجتمع الدراسة تكونت العينة من باس مبحوثة عينة الاراسة لتحقيق أهداف الدراسة تم استخراج عينة قصديه بطريقة كرة التلج وذلك لصعوبة الوصول الى معلومات حول القاصرات او بيانات للتواصل معهن وشملت 


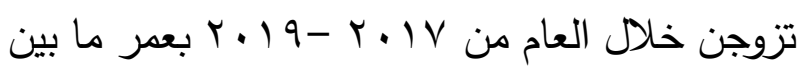
ד 1 وال1/ ا سنه وجميع المبحوثات لم يتممن تعليمهن الدراسي ومنهن من اكتفى بشهاده الصفوف الابتدائية من الصف الثامن للصف العاشر وتوزعت نسب الفتيات في مكان السكن حيث يعيش غالبية المبحوثات في المخيمات وكانت اغلب الفتيات من ذوات الدخل المتدني سواء قبل الزواج او بعده. يتضح مما سبق أن زواج القاصرات يعتبر ظاهرة مرتبطة بالطبقة الاقتصادية الدنيا (العاملة، الفقيرة) وذلك من منطلق عدة إجابات سوف نتاولها من خلال إجابات أفراد العينة: - إن -أن معظم المتزوجات القاصرات من اسر بلغ دخلها اقل من . . م وذلك بنسبة أر \% من أفراد العينة. -التحصيل العلمي للمتزوجات القاصرات متدني حيث \% بلغن الحاصلات على عاشر فأقل ما نسبتة من إجمالي أفراد عينة البحث.

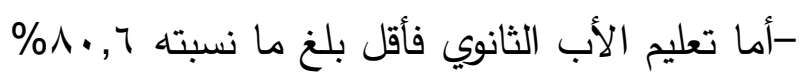
لآباء المتزوجات القاصرات. -وبلغ تعليم الأم الأمي ما نسبته ؟ ؛ ٪ \% من أمهات المتزوجات القاصرات. -أن من دافع زواج القاصرات كأن الوضع السيء لكأسرة حيث بلغ نسبة من تزوج لهذا الدافع بVY, وهو ما يوافق مع من اجبن أن الدافع لتحسين الوضع

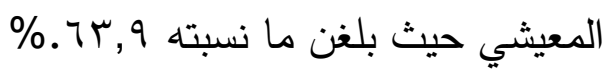

عرض وتحليل النتائج: بعد جمع البيانات واجراء الدقابلات قام الباحثًان بتفريغ المقابلات والملاحظات واستخدام التحليل اليدوي الياتي باستخدام الأقلام الملون لرصد التزميزات والنصوص

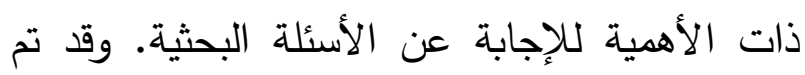
استخدام الاقواس على النصوص التي تم ترميزها وتضمينها في النتائج بحد الحد من التوقعات التهات والاقتراضات المسبقة بشأن تفسير البيانات، حتى يبقى البحاثان محايدان فيما يتعلق بتحليل النتائج وتعسيرها. و قد استخدت معايير trustworthiness لتقييم درجة الثقة المصداقية والقابلية للنقل والموثوقية والتأكيد؛ لتحقيق الدقة الدنهجية في الدراسة، وضمان الدصداقية بالإثارة إلى صحة البيانات من خلال وجود أكثر من باحث (مدير للجلسة، مسجل للملاحظات) خلال إجراء الدقابلات؛ للوصول إلى لى لئل أكبر قدر من البيانات، وقراءة الدقابلات مراراً وتكراراً

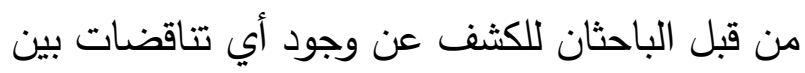
إجابات المشاركات، وإجراء التدقيق مع زميل البحث للوصول إلى أعلى قدر ممكن من المصداقية والتعرف على وجهات النظر المختلفة في تحليل البيانات. النتائج :

تم إجراء ب ب مقابلة مع متزوجات بسن مبكره(قاصرات) من محافظة جرش في الفترة القائمة

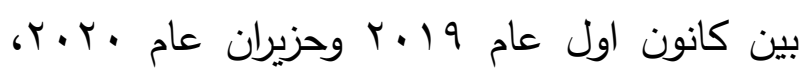
وذلك لدراسة مدى اثر الطبقة الاقتصادية في زواج القاصرات وتشكلت غالبية المبحوثات من فتيات 
عليها الباحثان من المبحوثات خلال المقابلة أما في المحور الثاني فقد كانت الإجابات مفتوحه وقابله للتوسع من خلا الأسئلة المفتوحة التي طرحها الباحثان على المبحوثات : المحور الأول : الخصائص الديمغرافية للعينة:
بعد أن تم عمل المقابلات قمنا بتفريخ الاستجابات للتحليل وكان عددها بـ مقابلة وسوف نستعرض فيما يلي: المحور الأول من المقابلة والذي احتوى على عدد

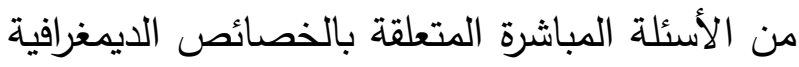
بطريقة عرض الجداول وتحليل البيانات التي حصل بل التيل (الجدول(1)

توزيع أفراد العينة حسب مكان السكن

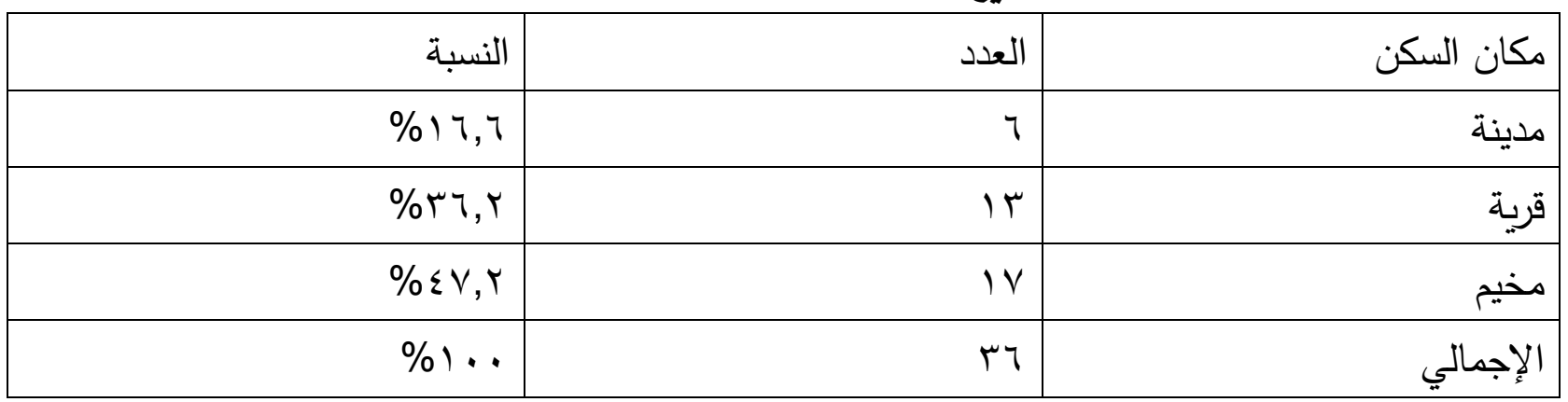

لها قوانين اجتماعيه تحكمها منها العادات والتقاليد يتبن من الجدول (1) أن المتزوجات القاصرات في

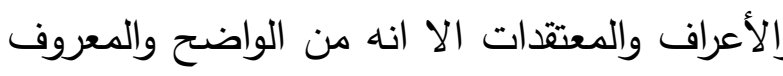

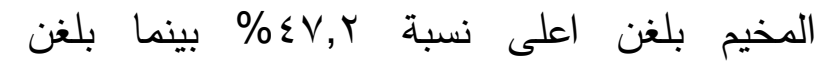

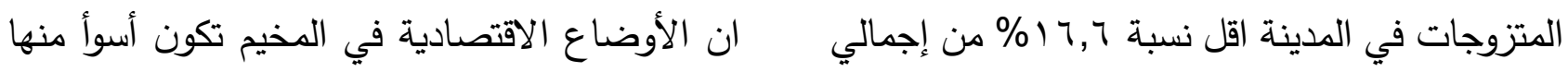
عينة البحث. كانت الاستجابات واضحه ومباشره من في المناطق الأخرى والتي تتسم بمستويات الأخل

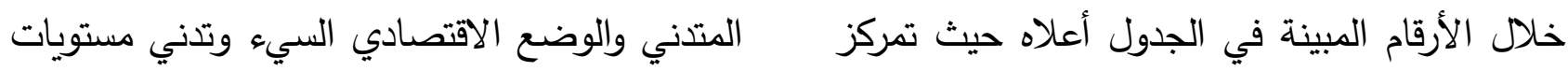
العدد الأكبر للزواج والذي اهتم بعامل مكان السكن التعليم، وزيادة عدد افراد الاسرة الواحدة.

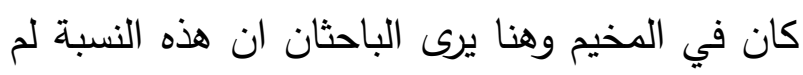

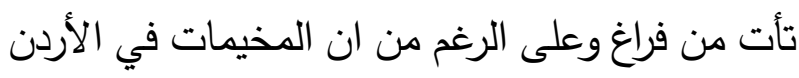




\section{(ب) ( الجدول)}

توزيع أفراد العينة حسب دخل الأسرة قبل الزواج

\begin{tabular}{|c|c|c|}
\hline النسبة & العدد & دخل الأسرة \\
\hline$\% \backslash 9, \varepsilon$ & $v$ & اقل من •or \\
\hline 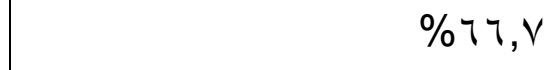 & rs & $0 . .-r_{0}$. \\
\hline$\% \backslash r, q$ & 0 & أكثر من . . \\
\hline$\% 1 \ldots$ & דr & الإجمالي \\
\hline
\end{tabular}

يتبن من الجدول(Y) أن نسبة دخل الأسرة للمتزوجات ذوات دخل الأسرة من • هץ-. .0 هن اعلى نسبة وبلغن

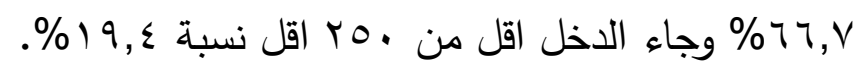
وهذا يقودنا إلى ان هناك نسبة كبيره من الاسر محدودة ومتدنية الدخل والتي قد تلجأ إلى تزويج بناتهن بسن مبكرة

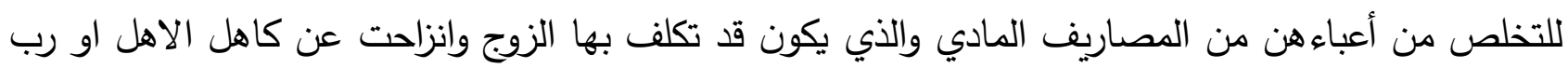
الأسرة حتى لو لم يذكرن ذلك خلال المقابلة لكن تبين لنا هذا في التحليل السابق .

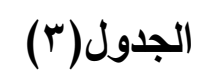

توزيع أفراد العينة حسب دخل الزوج

\begin{tabular}{|c|c|c|}
\hline النسبة & العدد & دخل الزوج \\
\hline$\% 11,1$ & $\varepsilon$ & اقل من •. r \\
\hline$\% \% 79, \varepsilon$ & ro & O... ro. \\
\hline$\% 19,0$ & V & اكثر من . .0 \\
\hline$\% 1 \ldots$ & ד & الإجمالي \\
\hline
\end{tabular}

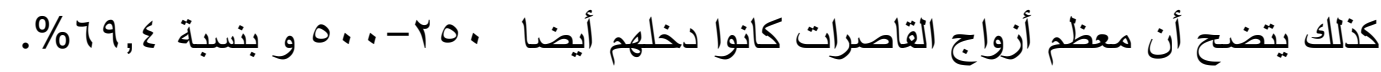

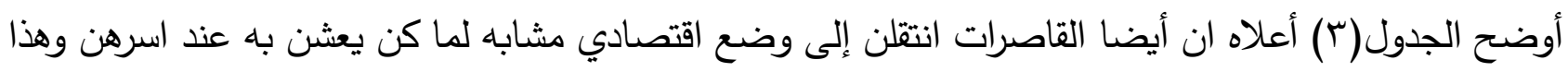
يقودنا إلى ان زواج القاصرات كان من بعض أسبابه هو التخلص من المصاريف الحياتية الماديه والتي قد يتكفل

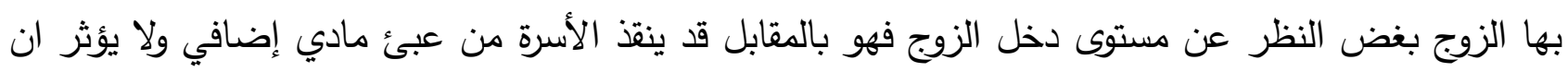

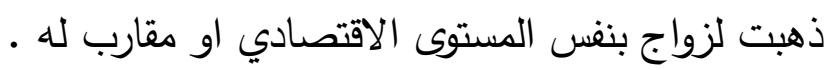




\section{الجدول( ) )}

\begin{tabular}{|c|c|c|}
\hline النسبة & 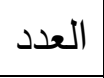 & التحصيل العلمي \\
\hline$\% .17,7$ & 7 & اقل من الصف السادس \\
\hline$\% 71,1$ & rr & من سادس للعاشر \\
\hline$\% r r, r$ & $\wedge$ & من عاشر للثانوية العامة \\
\hline$\% 1 \ldots$ & r & الإجمالي \\
\hline
\end{tabular}

يتبن من الجدول (§))أن المتزوجات القاصرات هن من ذوات التحصيل العلمي المتدني حيث بلغ نسبة التعليم الاقل من عاشر VV,V م من إجمالي المتزوجات. وهذه النتيجه طبيعيه لان التتاة القاصر أيضا هي التي تتزوج بسن مبكره قبل انهاء المرحلة الثانويه التي قد لا

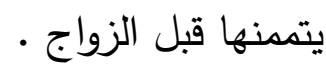

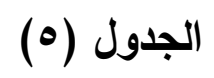

توزيع أفراد العينة حسب مستوى تعليم الأب

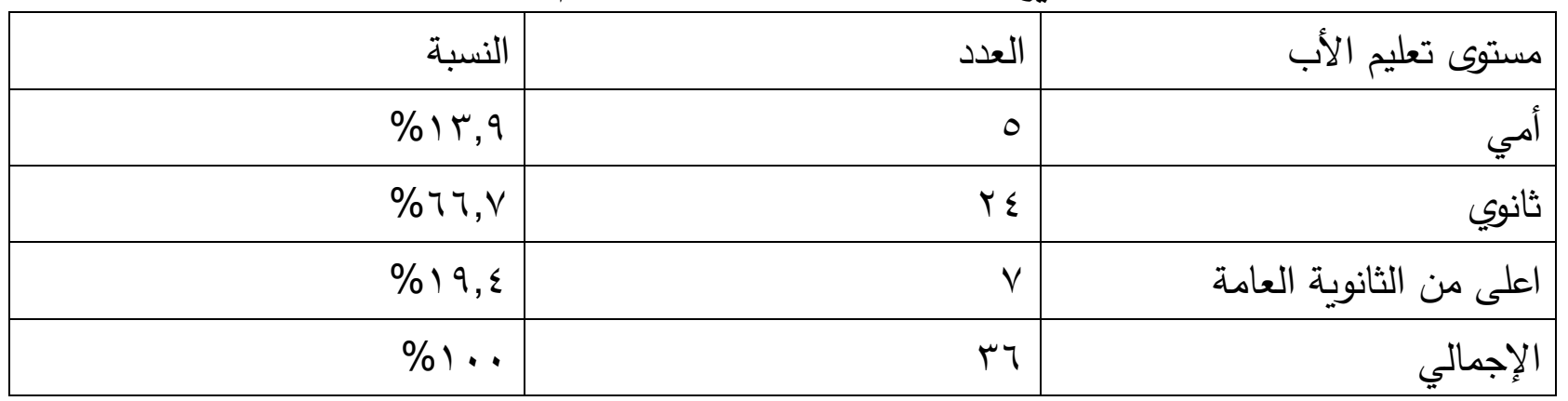

بالنسبة لتعليم الأب نلاحظ أن التعليم الثانوي حاز أعلى نسبة V7, >7 من إجمالي أفراد العينة. نجد في الجدول (0) ان النتيجه ان اعلى نسبة للتعليم للدى والد القاصر متدنيه دون الثانوية العامه وهذا قد يكون

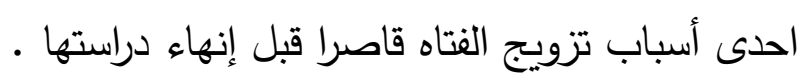




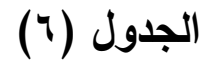

\begin{tabular}{|c|c|c|}
\hline \multicolumn{3}{|c|}{ توزيع أفراد العينة حسب مستوى تعليم الأم } \\
\hline النسبة & العدد & مستوى تعليم الأم \\
\hline$\% \circ \wedge, \varepsilon$ & YI & أمي \\
\hline \%rr,r & ir & 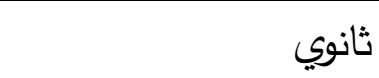 \\
\hline$\% \wedge, r$ & $r$ & اعلى من الثانوية العامة \\
\hline$\% 1 \ldots$ & ד & الإجمالي \\
\hline
\end{tabular}

الاستدلال بالنتائج التي ظهرت في البحث ومن خلال إدراج النسبة المئوية بالطريقة اليدوية لتعطي انطباع لتئن

$$
\text { الوضوح للبحث فيما يلي: }
$$

مناقشة النتائج: ولمناقشة نتائج المقابلات فقد جاءئ لاءت إجابات كل من المبحوثات على المحاور الأساسية في الدراسة من خلال طرح الأسئلة كمل يلي: - صلة القرابة بين الفتاة القاصر وزوجها:

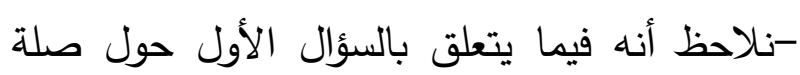

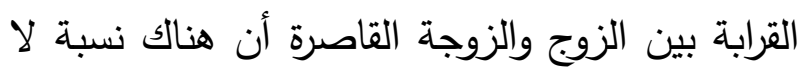

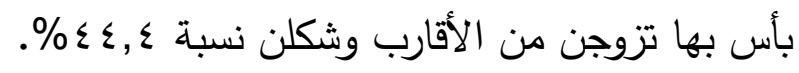

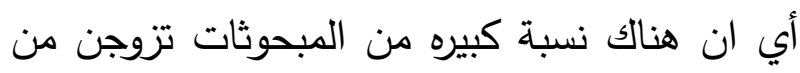

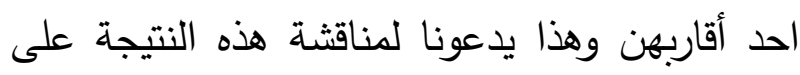

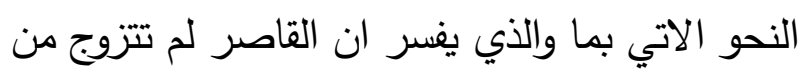
بيئة مختلفة وغالبا ا تكون مجتمع الأقارب متساوِ ماديا او متفاوت بدرجة بسيطة وهذا ما قالته احدى

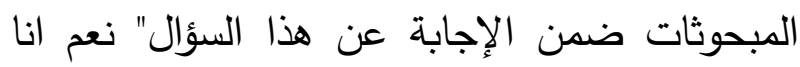

يتبن أن التعليم للام بين المتزوجات القاصرات يطغى

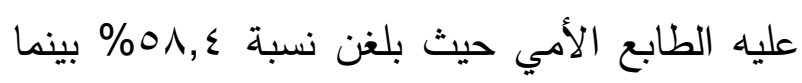

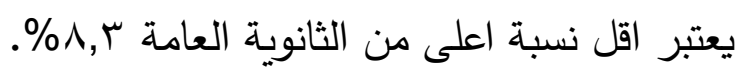
المحور الثاني من المقابلة :والذي تم فيه طرح

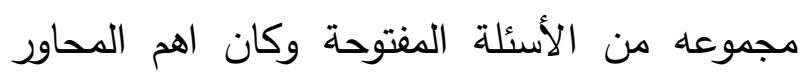
الرئيسية في البحث والذي اندرج تحتها مجموعة من الاسله الأسئلة الفرعية هي خمسة أفكار أساسية ذكرت خلال المقابلة بأسلوب سلس وسهل بحيث لا يؤذي مشاعر

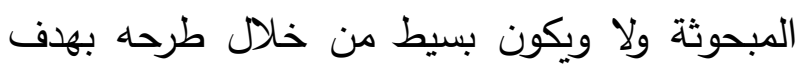
الحصول على نتيجة يمكن مناقشتها وتحليلها من فن ونه

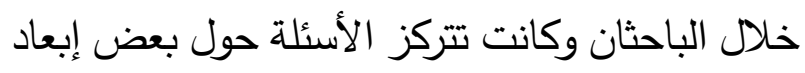
الطبقة الاقتصادية ومدى تأثيرها في زواج القاصرات وعمد الباحثان على ترتيبها بطريقة التسلسل من الأكثر استجابة الى الأدنى وبنفس الوقت استخدم الباحثان

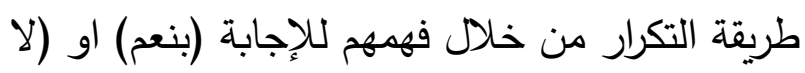
) حسب المبحوثه وسردها بطريقة تسهل على القارئ 
وهاذ اشي مهم لاهلي قالوالي خذي واحد بنعرفه ووين بدنا نغربك يعني ع الأقل الي بتعرفه احسن من الي ما بتعرفه بتضلي جنبنا لو صار عليك اشي بتكوني تحت عينا مش بكره يضربك ويهينك وانت ببلاد غريبه

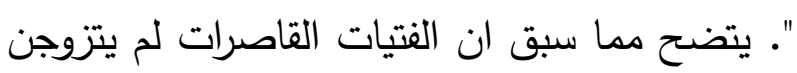
من بيئات مختلفة او حتى من ازواج وضعهم المادي لئي افضل بكثير من الوضع المادي الذي تعيش فيه أسرة

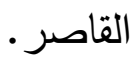
- زواج القاصر بمن هو أفضل من المستوى المادي لأسرتها:

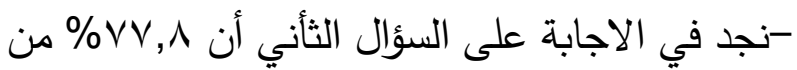
المتزوجات القاصرات تزوجن من هم افضل منهن

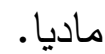
وعند الاجابه على سؤال الوضع المادي للزوج تحدثت احداهن قائلة :" انا بصراحه تزوجت من واحد ما بعرفه لهوليه بس هو معرفه لعمي كان بدور ع عروس وحكولنا وضعهم المادي كويس وبعيشك عيشه مليحه انا كنت وقتها صف عاشر واصلا مدرستتا م فيها للتوجيهي لازم انزل ع مدرسه ثانيه ابعد يعني وبدها مواصله وامي قال لي خذيه ترتاحي بتلاقي بيت وتتجبي أولاد

ووضعه المادي كويس بتتريحي وتزوجت منه" وفي نفس السياق اجبت أخرى باختصار :" اه هو وفي ونس

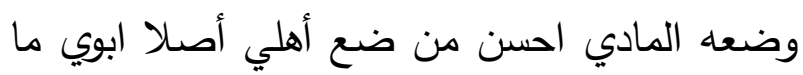

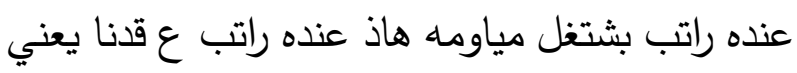

أخذت ابن عمي كنا دايما مع بعض من واحنا صغار انا كملت بالصف العاشر وهو راح يشتغل مع ابوه

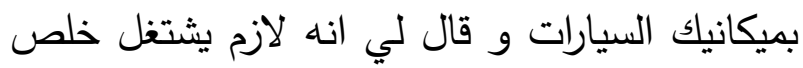
لانه بده يساعد أهله وان الدراسة م رح تفيد اشي الرجل

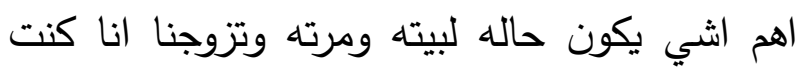
اصغر منه بأربع سنوات ولأنه ابن عمي وعارفينهخ لهن وتئه اهلى شجعوني وقالوا لي خليكِ بينا والي بتعرفه احسن لهن من الي م بتعرفه بعدين نهايتك تتجوزي تجوزي ع بكير بتشوفي ولادك وانت صغيره" وقالت أخرى " هو جوزي قرابتنا من بعيد بس احنا ساكنين بنفس المنطقة وبنعرفه وبنعرف اهله انا كنت بصف ثامن لما امه قالت لأمي انه بدها تجوز الولد

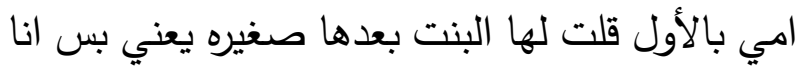

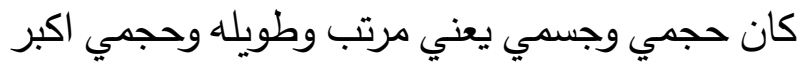
من عمري وبعدين انا نسيت الموضوع رجعت بعدما خلصت صف تاسع بالعطله الصيفي هاجا هو وابوه ع اهلي وخبروهم انا وافقت وتزوجنا" كانت مجموعه من المبحوثات قد ارتبطت بأحد اقارابها

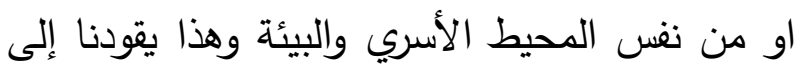
ان العادات والتقاليد قد يكون لها دور في زواج الفتاة بسن مبكر خاص عندما يكون الزوج احد الأقارب او لواج لون

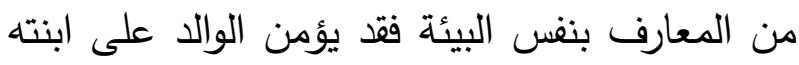
مع احد أقاربها او من نفس بيئته فهي قرببه منه ففي لمني كل لحظه ويكون بجانبها كما قالت حدى المبحوثات المتزوجة من نفس محيط بيئتها:" انا لما تزوجت (فلان..) كان من عنا القرابه بينا مش قويه بس بنعرفه 
وفي سياق اخر كان هناك عدد من المبحوثات ممن

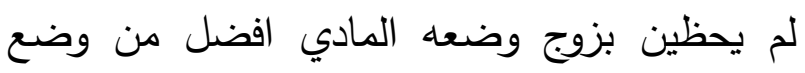
عائلاتهن ففي المقابل هن تزوجن من أفراد وضعهم المادي متدني وعاشن مستوى ماي اقل من مستواهن المادي قبل الزواج وكانت هذه الفئة قد تزوجن من من من من من من اشخاص بهدف الزواج فقط اما بمعتقد العادادات والتقاليد والستره والزواج افضل للبنت واما لانه كان لتهان

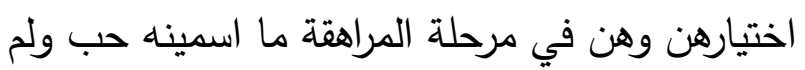
يعارض الاهل على مثل هذا الزواج حتى وان كان الزوج وضعه المادي سيء وفي هذا السياق تحدثت

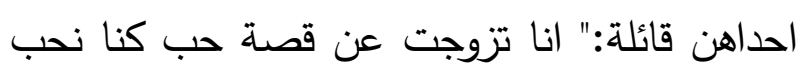
بعض هو كان اكبر مني بثلاث سنوات وحكالي انه

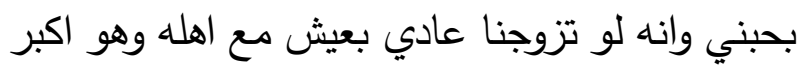

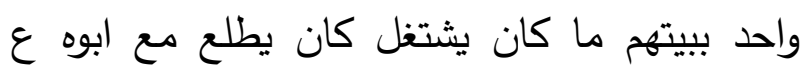

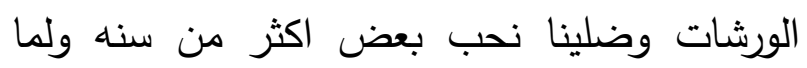
وطلبني من اهلي وتزوجنا بس بعدين هسا الحياه كثير صعبه صارلنا متزوجين سنين وشوي معنا ولا وسكنا عند بيت اهله بغرفه وبعدنا عندهم وهو بشتغل مع ابوه

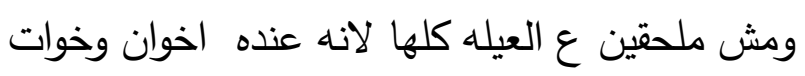

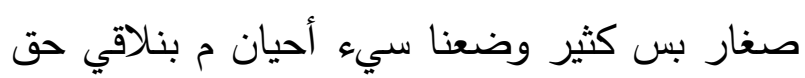

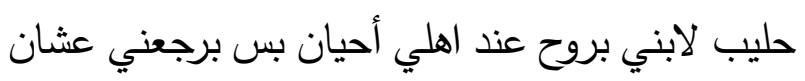

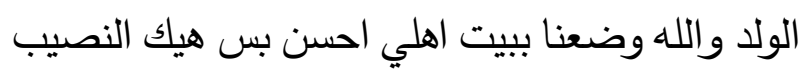

وفيما تحدثت أخرى قائلة:" انا وضعي اهلي المادي

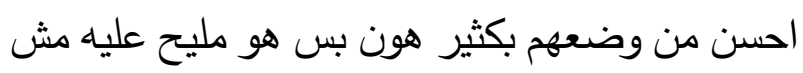
سيء انا تزوجت بعد الصف العاشر مباشره واهلي
وأخرى تحدثت بصيغة المستهزئ :" آه احسن من وضعنا مهو ابوي بده يتخلص من السبعة الي بالبيت

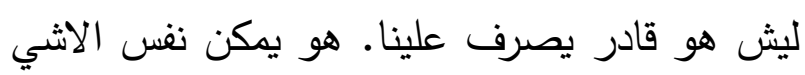
بس يعني ابوي بصرف على سبع بنات وثلاثة ولاد

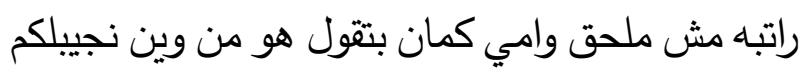

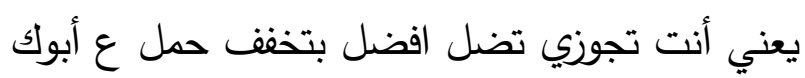

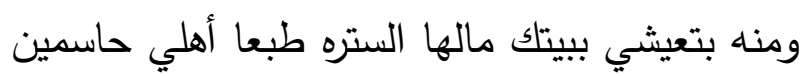
الامر الرجل م بعيبه غير جيبه وهاذ موظف أشغال

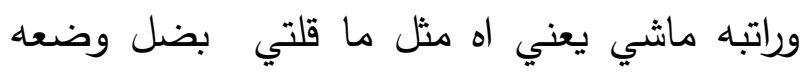

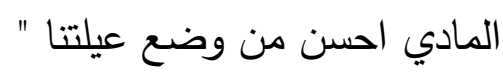
من خلال ما تقدم من استجابات المبحوثات على على على الوضع المادي فان اغلب المبحوثات انتقلن للعيش في لمني وضع مادي افضل من وضعهن المادي في الأسرة

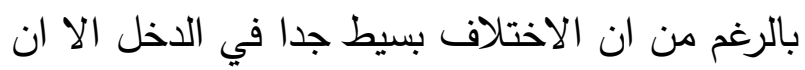
الاختلاف كان من العيش مع اسرة بعدد من الأبناء

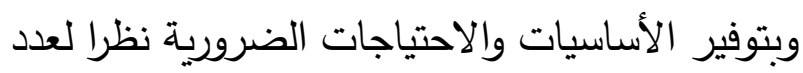

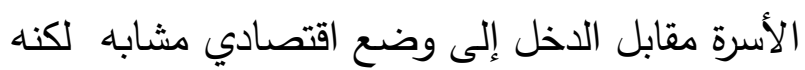

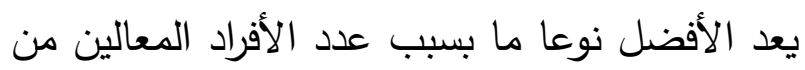

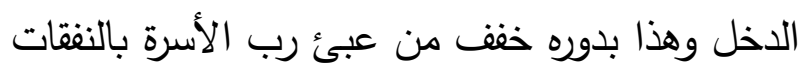

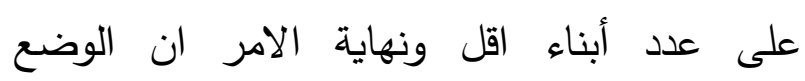
الاقتصادي لم يكن افضل بكثير ولم يكن مغاير الماء للوضع الراهن الذي تعيشه الفتاة القاصر في الأسرة

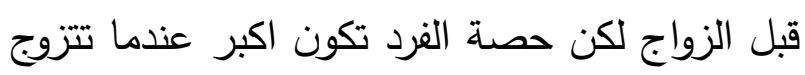

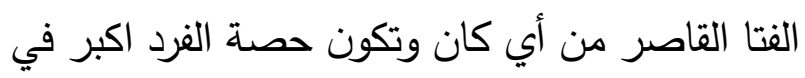

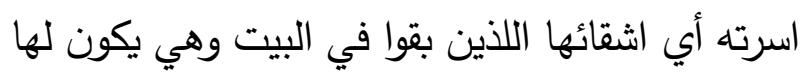
نصيب اكبر في حياة أخرى . 
تامه ولكن كان ذلك بمجموعة ظروف ودوافع جعلتهن يرضخن للامر الواقع والتي جاء فيها ان الوضع المادي السيء للعائلة كان دافع للزواج وأيضا الالحاح عليهن من قبل الاسره والاقارب من الخالات او العمات للزواج بسن مبكره وعدم اتساع ثقافتهن نحو حقوقهن بالتعليم وابداء الرأي فقد كان الرأي الاول

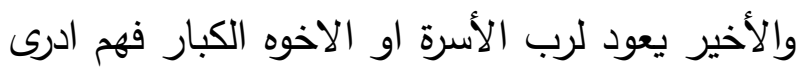

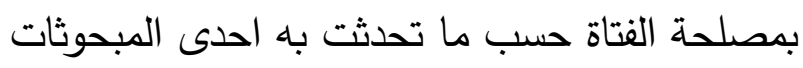
قائلة :" القناعه بالزواج هاي اشي بديهي يعني م دام اهلك حكل هالزله ويس عادي ممكن تقتنعي يعني م كنت بتذكر انه ببالي موضوع قناعه او مش قناعه هون هون لهون زواج بالنهايه رح نتجوز هاذ ولا غيره كان قبله واحد بلد متقدملي اهلي رفضوه حكو انه سوكرجي ( مدمن مشروبات روحيه) وبنفس الفتره اجو اهل زوي الحالي واهلي كانوا مواقين حكولي ابن عالم وناس وتتستري

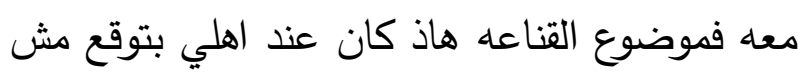
عندي"

وتحدثت مبحوثة أخرى :" قناعه بالزواج ؛ أصلا

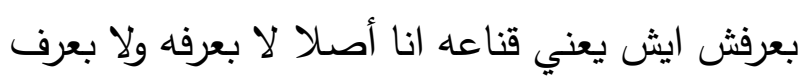
اهله ومقتتعه اني لبيتي ولاولادي وانه شكله كان لئن

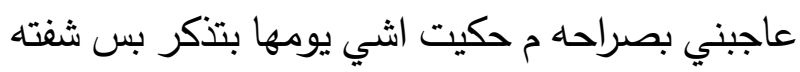
من الثباك ولما اجى اخوي وامي بقيت ساكته واختي لهي

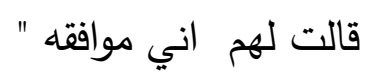
فيما قال عدد قليل منهم انهن تزوجن عن رضا وقناعة

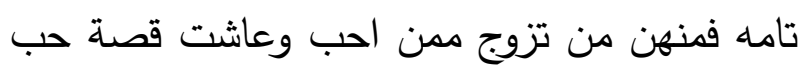
توجت بزواج ومنهن من تزوجت بقناعه عن عدم
وضعهم المادي كثير كثير مليح بس زوجي قاعدين

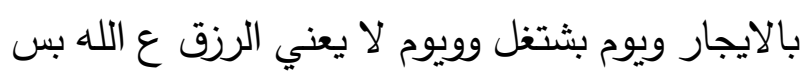

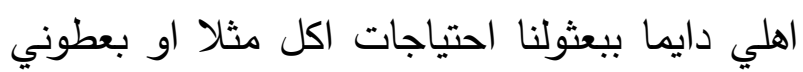
مصاري ولبس اهلي م قصروا بس انا تزوجت صغيره

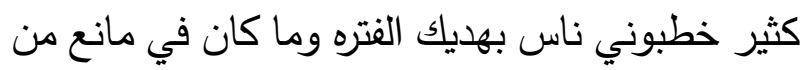
انه اتزوج لانه كمان خواتي تزوجن بهذا العمر " وهنا يتبين ان المبحوثات اللاتي تزوجن من ازواج ترون لتوني ذوي دخل متدني اقل من مستواهن المعيشي ماديا كن قد تزوجن لاسباب اجتماعيه وأخرى نفسيه ولم يكن للوضع المادي سبب رئيس او أساسي من زواجهن لتهنيأن

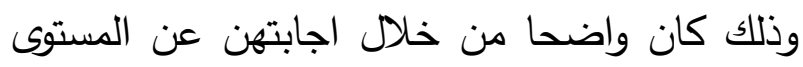
المادي للزوج والذي هو اقل من المستوى المادي للاسرة التي كانت تعيش فيها القاصر وجاء بحكم الاعراف والتقاليد والبيئة التي تسمح وتبارك الزواج

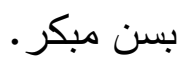
- إجبار الفتاة القاصر على الزواج من قبل أسرتها:

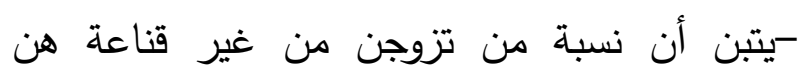

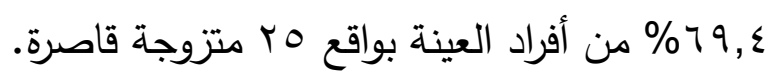
وهنا يجدر بالذكر نظرية التبادل الاجتماعي حيث تقوم

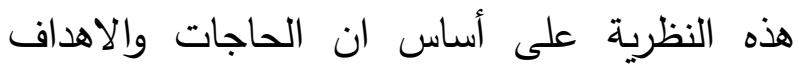
الخاصة هي الدحرك الأساسي، او الدافع الرئيس

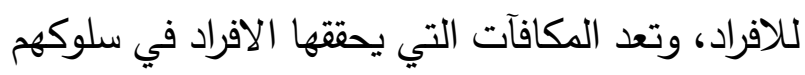
المتبادل هو أساس هذه النظرية. وفيما جاء يالاجبار على الزواج او كما قالت بعض هض لنطرده

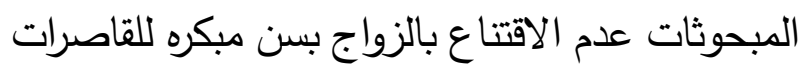

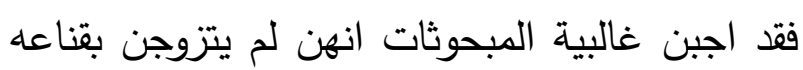


الأولى باعتقاده ان الزوج هو من يصرف على زوجته ويقوم على نفقاتها فهي تعطيه من جسدها وتربي له أبنائه وترعى لله شؤون بيته وشؤونه الشخصية فهو إلى بالنفق عليها منه وان ارادت ان تكمل تعليمها فلزوجها خيار ذلك فالبنهاية هو المستفيد الأول تحدثت مبحوثة في الإجابة عن هذا السؤال قائلة:" اه والله صحيح احنا وضعنا بالبيت الله يعين اهلي وابوي يعني لما اتجوز بخفف عنه حمل وكان الوضـع المادي بصراحه دافع الي قبل ابوي وامي انه اتزوج حكيت اذا تزوجت انا يمكن اختي الصغيره تقدر تكمل دراستها وبكون خف الحمل عن ابوي شوي" وأخرى تحدثت في نقس السياق :" اه طبعا يعني لولا المصاري كنت يمكن ابوي يخليني اكمل بس انا عارفه انه معناش فلوس واصلا رح اتزوج هسا ولا بعدين " فيما تحدثت أخرى بغصه:" يقطع المصاري منن الدنيا بتخربلك حياتك او بتزبطها يعني هسا لو ابوي ما توفى وتركنا لامي كان يمكن وضعنا احسن يمكن يخليني اكمل دراسة واتوظف واصرف عليهح كمان بس الحمد لله رب العالمين الدنيا هيك كلها مصاري وفلوس " هكذا كانت الاستجابات لدى المبحوثات والتي تفضي إلى ان الوضع المادي السيء لله علاقة قوية بزواج القاصرات ويعد عامل واضح وقوي يدفع الاهل إلى تزويج بناتهن بسن مبكر • - كان الزواج بهدف تحسين الوضع المادي: -بلغ نسبة من اجبن أن الزواج جاء بدافع تحسين الوضع المعيشي 9,rا7\% من أفراد العينة.
رضاها بظروف بيت أهلها وانها تريد الانتقال لمان اخر مهما يكن هذا المان وان الزواج هو الخيار الاسلم والمضمون لايجاد حياة أخرى اقل معاناة سواء معاناة ماديه او نفسيه وتحدثت قائلة:" انا م كنت مرتاحه ببيت اهلي اخواني دايما بضربوا ومعصبين وبنشتخل ليل نهار وراهم ووضعنا المادي مش كثير كويس كنت زهقانه بيت اهلي وبصراحه تعبانه ودايما ببالي متى رح اتزوج وكنت اه مقتنعه كثير بالزواج لانه بشوفه الحل الأفضل عشان اخلص من عيلتنا وصار النصيب والحمد لله " الهروب من الوضع المادي في الاسره نحو الزواج: -كذلك نجد أن دافع الزواج من اجل الوضع المادي للأسرة كأن مرتفع وذلك بنسبة r, \% من اجمالي عينة البحث. كانت هنالك نسبه كبيره من استجابات المبحوثات نحو الزواج بدافع الوضع المادي السيء للاسرة وهذه النتيجة قد تكون ابرز نتيجة في البحث والذي يدل على ان زواج القاصرات له لله واقعيه وحقيقة ترتبط بالمستوى المتدني للأسرة والتي تدفع الأهل إلى تزويج بناتهم بسن مبكره على الرغم من عدم الإفصاح في ذلك بشكل واضـح وقد يقود الوضع المادي السيء لرب الأسرة إلى اللجوء لتزويج بناته بسن مبكره تحت شعار ومبرر العادات والتقاليد وطلب الستره للفتاة متناسيا ان هنالك سبب اخر يعتبر أساس ورئيسي في بعض الأحيان وهو التخفيف من العبئ الادي الذي ينفقه على ابنته خاة عندما يفكر في تعليمها ورعايتها من 
ع- -اتخاذ إجراءات اقوى في الهحاكم الشرعية وتحديد قوانين وتشريعات ترفض الزواج المبكر بغض

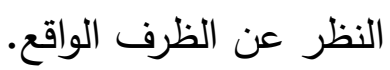
0- - إجراء المزيد من الدراسات حول ظاهرة زواج القاصرات وعلاقتها ببعض العوامل الاجتماعية كالتتكك الاسري والتتشئة الاجتماعية. المراجع

أولا - المراجع العربية:

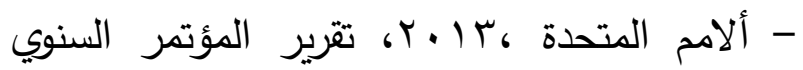

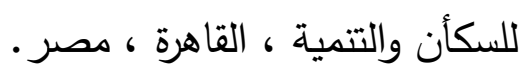

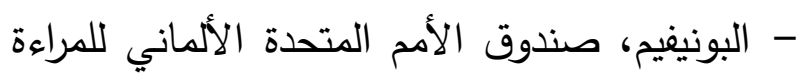

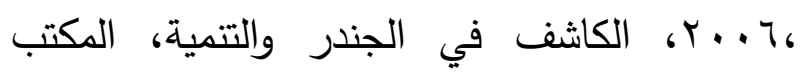
الإقليمي للدول العربية - اليونيفيم، عمان ، الأردن.

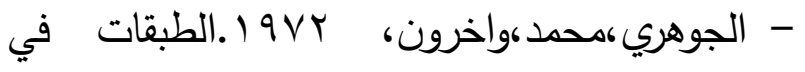
المجتمع الحديث. الإسكندرية: دار الكتب الجامعية. - خليل، معن،99919، نظريات معاصرة في علم الاجتماع، دار الثروق، عمان، الاردن.

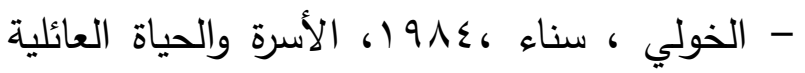
كبيروت ،دار النهضة العربية.

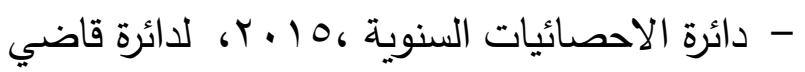
القضاة في الأردن.

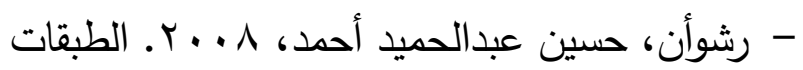

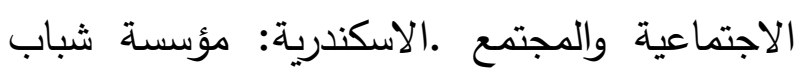

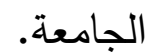
- زحلوق ،مها، ووطفة، علي، 199 1 ، كاتجاهات الثباب نحو عادات الزواج ومظاهره: دراسة ميدأنية
كما تحدثا في الطرح السابق فان تحسين الوضع المعيشي للفتاة القاصر كان له دور كبير وواضح في استجابات المبحوثات واللاتي تزوجن هرباً من الواقع

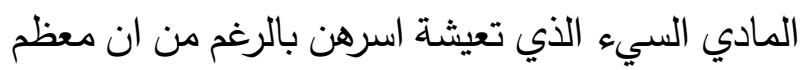

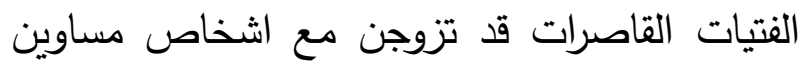
لاسرهن بمستوى الوضع المادي او حتى اقل من

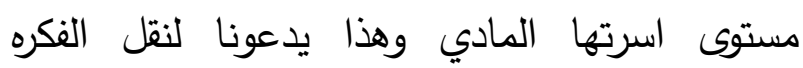
الأساسية من الزاج بهدف تحسين الوضع المادي

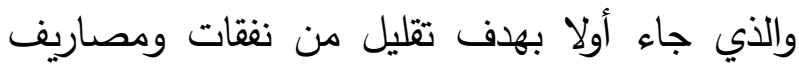
الفتاة على كاهل اسرتها وانتقالها إلى رجل اخر مسؤول

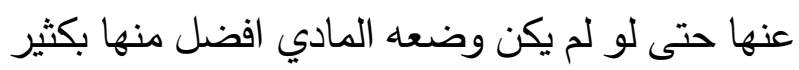
فهي هنا تدكون هي او عائلتها خفقوا من العبئ الاقتصادي الواقع على كاهل احد والداها او كليهما وهذا ما دفع افتيات للزواج بسن مبكرة دفع الاهل الموافقه على الزواج والذي قد تترتب عليه أعباء كثيره بعد الزواج لكن يكون الزواج قد حصل . التوصيات:

1- وضع حلول لمعالجة المشكلات الاقتصادية التي تعاني منها بعض الأسر التي تلجأ إلى تزويج التهات

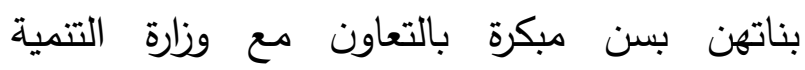
الاجتماعية. r - عقد ورش وندوات وحلقات نقاشيه حول خطورة الزواج المبكر خاصده في المجتمع المحلي وندوات وحلي ومؤسسات التعليم مثل المدرسة. r- تفعيل دور الأخصائي الاجتماعي في فئن المدارس والنوادي الثقافية والاجتماعية المحلية. 
- قانون الأحوال الشخصية الأردني، . . . .

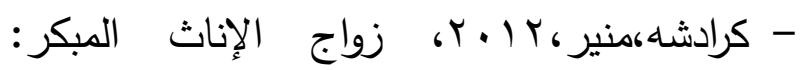
محدداته وآثاره الديمغرافية في المجتمع الأردني،(دراسة تحليلية)، المجلة الأردنية للعلوم الاجتماعية المجلد 0،

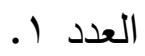

- المصدر التقارير الإحصائية السنوية لدائرة قاضي القضاة 9 1 ـ ب، الأردن.

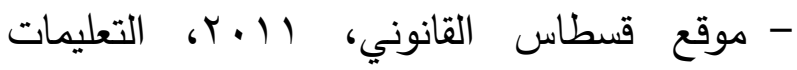
الخاصة بمنح الاذن بالزواج لمن هم دون سن الثامنة

$$
\text { عشرة. }
$$

- وسترمارك، ادوار، ( + . r، موسوعة تاريخ الزواج ،(ترجمة مصباح الصدد، وصلاح صالح وهدى رطل)، بيروت: المؤسسة الجامعية للدراسات والنشر • - اليونيسيف ، منظمة الأمم المتحدة للطفولة: ع . . r، كبيرة على اللعب صغيرة على الزواج .

\section{المراجع الاجنبية:}

-Fowler, R., 2014, Syrian Refugee Families' Awareness of the Health Risks of Child Marriage and What Organizations Offer or Plan in order to Raise Awareness, SIT Graduate Institute/SIT Study Abroad.

-lain,S. and Kurz., 2007, New Insights on Preventing Child Marriage: A Global Analysis of Factors and Programs, International Center for Research on Women ICRW(, Washington DC).
في محافظة طرطوس، مجلة بحوث جامعة حلب: سلسلة الاداب والعلوم الأنسأنية،العدد 9 ؟.

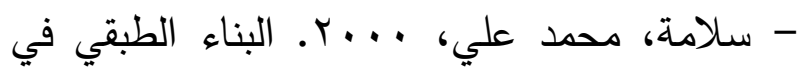
الريف المصري. الإسكندرية: دار الوفاء للطباعة

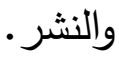

- السيد، رشاد غنيم،م . . ب، النظرية المعاصرة في علم الاجتماع، دار المعرفة الجامعية، الإسكندرية . - صالحي،ميس، Y (.Y.، وضع المرأة في قأنون العقوبات رقم(7 ( ) لسنة ، ج 9 (،الحوار المتمدن،العدد $.29+9$

القاصرات،دراسة ميدأنية ، العراق، بغداد.

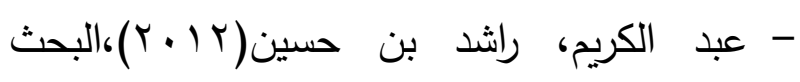
النوعي في التربية: دار أسامة للنشر والتوزيع، الرياض.

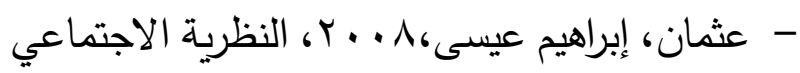
المعاصرة، دار الشروق للنشر والتوزيع الأردن.

- Nadelson, C., \&Notman, T.: To marry or not to marry:1981 A choice. American Journal of Psychiatry, 138 (10), ,pp. 1352-1356.

- Special tabulations by PAPFAM,using 2011 Lrea Women integrated Social and Health Survey(1-WISH).

https://www.un.org/ar/universal-declarationhuman-rights/index.html.-

http://qiistas.com/jor/index.php?mod=BS\&acti on=View [Nov.20,2013]- 


$$
\text { عبله عبد الرحيم محاسنه و فواز حمدان رويشد العازمي }
$$

\title{
The phenomenon of child marriage and its impact on the economic class: A qualitative descriptive study
}

\author{
Dr. Abla Abd Al-Rahim Mhasneh \\ Academic Degree: $\mathrm{PhD}$ in Sociology \\ Part-time lecturer / Irbid National University \\ Dr. Fawaz Hamdan Al-Azmi \\ Academic Degree: $\mathrm{PhD}$ in Sociology \\ Ministry of Social Affairs and Labor - State of Kuwait
}

\begin{abstract}
Summary. the aim of the study: The study seeks to shed light on the extent to which the marriage of minors is affected by the economic class in terms of sociology. Methodology: The two researchers used the qualitative descriptive approach for its suitability for the purposes and objectives of the study in providing a description and analysis on a sample of minors in Jerash governorate. The sample consisted of 36 minors who were chosen by the snowball method. Through the standardized interview tool, which contained two axes, the first axis is demographic information and the second axis is a set of open questions. They were interviewed and the responses were analyzed and discussed, and the study concluded with a set of results: The most important of them was that the marriage of minors is considered a phenomenon linked to the lower economic class (working, poor) and that is based on several answers, where the first order came that most of the underage married women were from families whose income was less than (500) Jordanian dinars. The poor economic situation of the family came as the second most important driver for marriage Underage girls, and to improve the living situation, and in the third place came those who were forced into marriage at an early age by the family. Conclusion: The phenomenon of underage marriage is affected by the economic class in society, and one of the most important causes of the phenomenon of underage marriage is the economic situation of the minor girl's family.
\end{abstract}

Key words: economic class, child marriage, qualitative descriptive study, phenomenon. 